\title{
9
}

\section{Generic Terms for Subsections ('Skins') in Australia: Sources and Semantic Networks}

\author{
Patrick McConvell and Maïa Ponsonnet
}

\section{Introduction}

This chapter examines the generic terms for subsections in Australiathat is, the general terms that are applied to them as an institution in various Aboriginal languages. These Aboriginal language terms are roughly parallel to 'subsection' in academic English or 'skin' in more vernacular and Aboriginal English. As will be argued later, 'skin' is actually a loan translation from one of these Indigenous terms in one part of the country; however, generic terms have a variety of sources in different areas. The generic terms usually originate from words with different meanings, such as body parts or emanations like sweat and smell, and may also have been terms for other social categories, such as 'totemic' clans, before being applied to subsections. The polysemy of the generic term for 'skin' with these source meanings may continue in the current language. For example, in Dalabon, the term for subsection is malk, which also means 'weather/season'; thus, one can ask, 'What is your malk?', or 'What is your subsection (weather/season)?'

We are not concerned with specific terms for individual subsections in different languages, which have a different history unrelated to the history of the generic terms (McConvell 1985a) and which are being explored 
in-depth in the AustKin II ('Skin and Kin') project and in chapters in this book (McConvell \& Dousset 2012). We also do not go deeply into the generic terms for other social categories, such as sections and totems. In Australia, social groups such as phratries or clans are often associated with things in the world that represent them emblematically. For instance, matriphratries on Croker Island are represented by sun, fire, rock and pandanus. In many places, totems are animals such as species of mammals, reptiles, birds and bees. There are semantic connections between these totems and the generic terms for subsections, which we outline, but this topic will be explored more fully on a different occasion.

In the Dalabon corpus of the second author, the generic term for subsections was used mainly to discuss relationships between spouses or potential spouses, especially when the adequacy of a given relationship was being questioned. Thus, the existence of a generic term facilitates explicit judgements on the conformity of behaviours with rules of kinship, and accentuates the binding power of this social structure. The existence of such terms is therefore socially significant, and the way they are used deserves indepth study from the point of view of anthropological linguistics. However, this is not the task we devote ourselves to in this chapter; instead, we focus on issues of lexical and typological semantics related to word forms used as generic labels for subsections. Further data on usage would certainly assist in the analysis of semantic shift, since usage provides the bridging contexts that determine semantic change. However, collecting data on usage for 45 languages was not possible in the context of this preliminary research; thus, the question of usage is open to further research.

We have assembled generic terms for most subsection systems and their other meanings (where available). We show here that there are semantic connections between generic terms across the area where subsections are found and beyond, and we represent this on a semantic map. A semantic map (François 2008; Haspelmath 2003) is not a geographical map, but one that shows where polysemous words have put more than one sense together (such as those that have a sense like 'subsection' and a sense like 'body'). In this case, we extend the function of a semantic map to demonstrate that it also corresponds closely to the geographical map. Polysemies (or 'colexifications' in François's terminology, which we follow) occupy discrete areas on the map, either because of inheritance of the colexification in a language family or subgroup, or diffusion of the colexification. This allows us to trace the history of these semantic associations, which also relates to the layering of different social category systems as they diffuse over time. 
There have been claims that there is a fundamental conceptual unity in many or all of the subsection and section systems, related to supposed differences in bodily or mental characteristics of members of these different social categories (e.g. von Brandenstein 1982); however, this hypothesis has been challenged (McConvell 1985b). Here, we study the colexifications of generic terms for subsections of around 45 languages (including some dialect varieties). We make an inventory of the domains to which they relate etymologically, and assess whether these domains concentrate mostly on bodily or mental characteristics, as previously hypothesised.

\section{Subsections}

Subsections are a system of eight sociocentric categories. All people who recognise each other as being in the same world of kin-which may extend far beyond a language group and even beyond the confines of Indigenous people—have a 'subsection' or 'skin' name. This is normally determined by the 'skin' of their parents. The 'skin' name is different from the skin of either parent but the parents' skin identities determine that of the child. Each of the eight categories has a particular kinship relationship with a person (an Ego). This means that when a person with a particular identity meets someone, even a stranger, they can immediately call each other by an appropriate kinship term, based on kinship links-known or supposed. For instance, if you meet someone with the same skin name, that person is your 'brother' or 'sister', their mother is your 'mother' and so on. There is also one skin (or sometimes two) that is 'straight' for any Ego-meaning that they are a legitimate marriage partner. (For more details of the system, see Chapters 1 and 3.)

In contrast, sections only have four terms. Each section represents a combination of the kinship types in two subsections. For instance, in a section system, one's own section contains people who are 'mother's mother' to Ego, as well as those who are 'brother' and 'sister'. In the most widespread type of subsection system (which we shall call 'classic'), 'mother's mother' is in a different subsection from 'sister'.

Linguistic investigation has revealed that the subsection system grew out of the meeting of two section systems, from the west and from the north. These two systems engaged in a particular type of marriage circulation that brought the new and more complex system into being, around the Katherine area of the Northern Territory (McConvell 1985a). From there, 
the new subsection system spread west into the Kimberley, south into Central Australia, north-east into Arnhem Land and east along the Gulf of Carpentaria and through the Barkly Tableland into the westernmost part of Queensland.

Around the periphery of this area of subsection expansion are other areas of sections - in Western Australia, parts of Central Australia (see Chapter 10) and very large areas of Queensland and New South Wales (see Figure 30; for the possible origin of sections in Queensland, see Chapter 8). In at least some of the areas where subsections are located, there were sections at some previous period ${ }^{1}$ that have now disappeared. In other areas where subsections are found, there were and are still other social category systems, such as matrilineal totemic clans and phratries. The adoption of generic terms for such categories to refer to subsections is part of the story that we will unfold here.

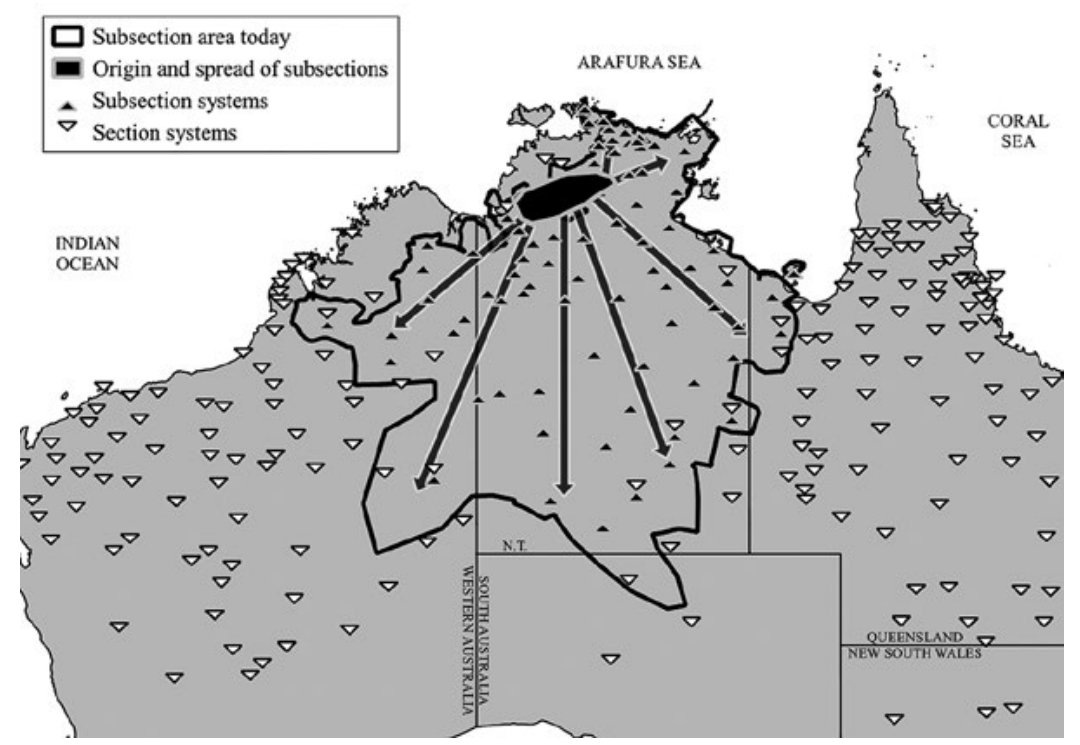

Figure 30: Map of distribution of sections and subsections.

Source: William McConvell.

1 McConvell $(1996,1997)$ estimated that the origin and beginning of subsection diffusion took place around 1,500 years ago. Harvey (2008) implied a date several thousand years earlier by reconstructing subsection terms to Proto-Mirndi. Mirndi is a very old family judging by the low number of lexical cognates. While both these hypotheses are tentative and more work is needed, we favour a date nearer to McConvell's and are doubtful about the Proto-Mirndi reconstruction. Absolute chronology is not part of the current exercise, but this chapter contributes evidence to relative chronology of subsection spread, which may be converted to absolute chronology by calibrating linguistic changes to archaeological dates (cf. McConvell \& Smith 2003). 


\section{Methods}

The terms for subsections (and a few sections) were assembled into a spreadsheet showing:

- their language

- the generic term for subsection in the language

- 'strict' colexifications, i.e. other senses of the subsection term

- 'loose' colexifications, i.e. senses to which a word relates etymologically

- other terms possibly related in form (whether cognate or borrowed)

- the source (e.g. dictionary, ethnography or pers. comm.)

- notes.

Some of this information was also entered into the AustKin II online database. So far, there are data for around 45 languages (including some dialect varieties), with at least 37 distinct colexifications (of course, these figures are indicative, since neither language delimitations nor sense delimitations are entirely discrete). This sample is large enough to identify patterns and articulate hypotheses that will be discussed later on. However, there are many instances in which we have no data or inadequate data on generic terms for subsection for the languages that have subsections. No data might mean that there was no generic term or that it was not recorded; where a term had been recorded but without a colexified sense, it might have been that there was no polysemy or that it was not recorded.

In almost all languages for which we have data, the generic term for subsection colexifies or loosely colexifies another meaning-that is, the generic term also has another sense in the same language or in a neighbouring language. There were a few exceptions to this general observation:

- There are a few languages that have no generic term for subsection.

- There are a few languages that have a vague term-for example, 'something'.

- There are a few languages that use 'kind' including suffixes-for example, 'What kind are you?' means 'What subsection are you?'

- In a number of languages, the term for subsection is the same as that for another social category. For instance, in the Victoria River District and western Arnhem Land, the colexification is between 'matriphratry' 
and 'subsection'. At least one family (Bunuban-two languages) has a term that only colexifies another social category-patrimoiety-and does not have a more concrete colexification or etymology of which we are certain.

- A few languages have a term for subsection that is not obviously a word for something else in the same language nor, as far as we have discovered, relates etymologically to such a word in another language, which suggests a further remote etymology. This is a rare occurrence and only two examples have been found so far-both in the same language Wanyi: nginyngi (Mary Laughren [pers. comm.] incorrectly recorded this as nini in an earlier source) and kuku. It is possible in this case that there could be other connections that have not yet come to light. ${ }^{2}$

We have constructed a 'semantic map' using the methods of François (2008). We refer the reader to this publication, the review by McConvell and Ponsonnet (2013) and Haspelmath (2003) for more comprehensive discussions of semantic maps and associated methods. ${ }^{3}$ We began with the sense 'subsection' as a 'pivot' or starting point and then traced a network in which the meanings that constituted plausible semantic extensions of one another, represented by individual cells, were located spatially closer to each other. This process, as we have used it, is not based on a standard way of analysing semantic composition or semantic distance, but rather based on subjective judgement and our knowledge of polysemies and semantic extensions in Australian languages. Of course, this reliance on intuition is not satisfactory. Thus, the organisation of the cells on the map is tested against actual colexifications, whereby a line is drawn to connect two senses when these senses are colexified by at least one language. If two senses have been placed adjacent to each other but are not found to be colexified in any language, then the map is 'falsified' and subsequently reorganised.

2 Subsections in eastern Mirndi languages have suffixes -nginytya (masculine) and -nginytyu (feminine) (e.g. Jingulu: Pensalfini 2003, pp. 12-3). It is possible that the -nginy here is related to the Garrwa-Wanyi word for generic 'subsection' and the Jingulu word for 'seed' nginytyu. The Mirndi languages have masculine and feminine genders; however, -tya and -tyu are not the regular forms of the gender suffixes, nor do they relate to the gender suffixes in Wakaya, a neighbouring PamaNyungan language $(-u$ [masc.] and $-i[\mathrm{fem}]$.$) . However, the eastern Mirndi suffix -n g i n y t y u$ is also homophonous with the word for 'seed' in Jingulu.

3 Cf. Evans (1992a), Evans and Wilkins (2001) and Jurafsky (1996) for examples of graphic representations of semantic networks. Schapper, San Roque and Hendery (2016) presented colexifications of 'tree', 'firewood' and 'fire' in Australian and Papuan languages projected on to geographical maps. 
In the corpus used by François (2008), some languages colexified 'breathe' with certain senses, and other languages did so with other senses again, with partial overlap across languages. The patterns of colexification found across languages can be summarised in the form of a semantic map taken from François (2008, p. 185) and reproduced in Figure 31. This is a simplified initial network with the pivot 'breathe', bringing in evidence from a number of languages in various language families from different parts of the world. The links between adjacent items reflect semantic proximity in synchrony and do not claim to represent diachronic relations. However, each link could, and many do, have a counterpart in diachronic change. ${ }^{4}$

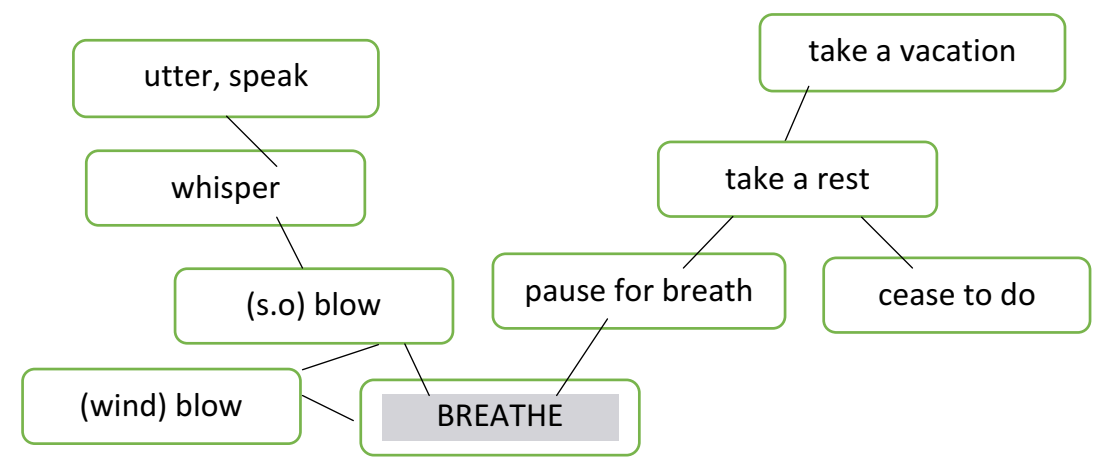

Figure 31: The first semantic map for \{BREATHE\}.

Source: After François (2008, p. 185).

In practice, it was sometimes impossible to find alternative connections when the map had been 'falsified'. In some cases, a 'step' in the chain of semantic associations might be 'missing' - that is, it was not represented in our corpus. An example of this would be as if no language colexified 'pause for breath' and 'take a rest' in Figure 31. Some would colexify 'breathe' and 'pause for breath', and some 'breathe' and 'take a rest', but none would display the whole chain as represented in Figure 31-perhaps because some languages in which the word for 'breathe' also means 'take a break' have lost the sense 'pause for breath'. In our case, such 'missing' colexifications may result from gaps in our data. Alternatively, the missing senses might be absent in synchrony, but could have existed historically and disappeared-'washed away' by history. François's method explicitly

4 Whether these are all potentially bidirectional or some only unidirectional is not investigated, nor is the issue of whether all such changes pass through a 'bridging' polysemy as in the hypothesis of Evans and Wilkins (2000). See also McConvell (2013, p. 195) on the hypothesis for kinship terms. 
sets historical concerns aside; however, our purposes are slightly different. Therefore, when a conceptually attractive connection between two senses is missing from the data, and no alternative conceptual association seems plausible, cells representing the senses in question are linked with a dotted line, indicating that the association between the two senses is hypothetical.

This method is heuristic, based on meanings or senses of words available in sources, without an explicit semantic theory or decompositional practice as a foundation. We do not concern ourselves initially with whether a sense of a word is contextually determined or an entirely separate meaning. Such considerations may come into play after an entire semantic map is assembled, as a kind of 'bootstrapping' method. In our approach, we go beyond the typological semantic map to a geographical map of the spatial distribution of colexifications, and then add the historical dimension to the geographical map.

\section{The Maps}

\section{Semantic Map of the 'Subsection' Network}

Using the method previously mentioned, we constructed a semantic map of the network of colexifications involved with the generic term for subsection. Initially, this was completed without reference to geographical distribution. We identified nine main trends of colexification in the data and a few other minor ones (they are listed here in the order of presentation adopted in this section):

1. other social categories

2. dermis

3. smell, flavour and associated senses

4. body

5. head and associated attributes

6. name ('what are you called?')

7. time, country and associated senses

8. shadow (uncertain)

9. country, times and associated senses. 


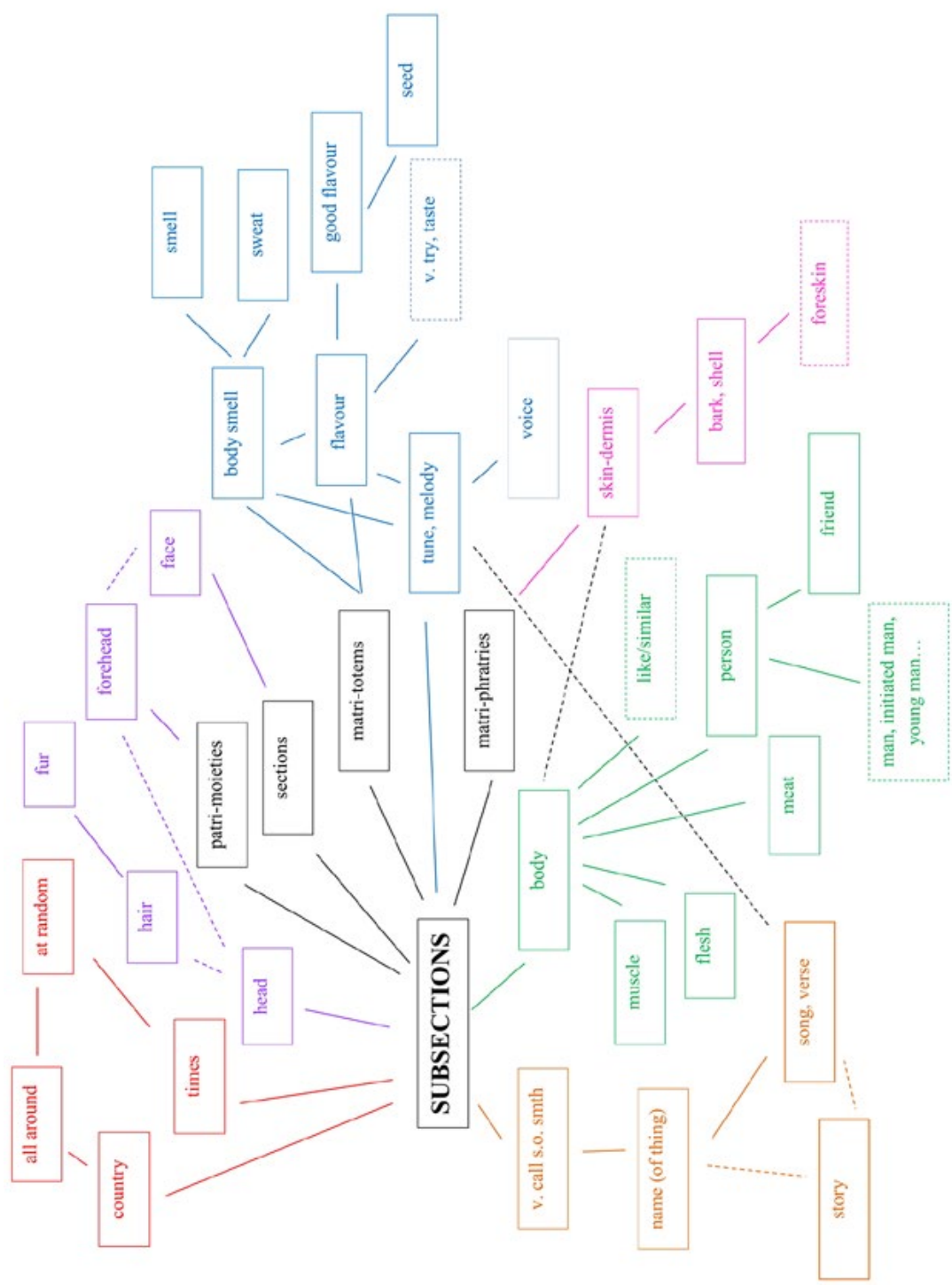

Figure 32: Semantic network of \{SUBSECTION\} (generic term) for the Australian languages surveyed.

Source: Authors' work.

Cells represent units of sense strictly colexified with the pivot 'subsection' (i.e. other senses of the words that mean subsection). Dotted cells represent units of sense loosely colexified with the pivot (i.e. with some historical relationship to the pivot). Lines between cells indicate that the two senses 
are actually colexified (i.e. that there is a word with these two senses) in at least one language. Dotted lines between cells indicate that we have hypothesised that the senses in question may be colexified in a language that is not included in the sample, or may have been colexified in the past.

\section{Geography}

To some extent, the different colexifications of subsections map on to discrete and continuous geographical regions. Therefore, the semantic clusters identified on the semantic map also cluster geographically. The match is not perfect, but the mismatch effect may be amplified by the fact that we do not have information for all languages in which subsections were used, and some languages in the same regions do not have the subsection system. As a result, the geographical map has 'gaps' (see Figure 33). Nevertheless, for most clusters, the geographical trends are relatively clear. In the following paragraphs, we discuss the clusters and their areal distribution.

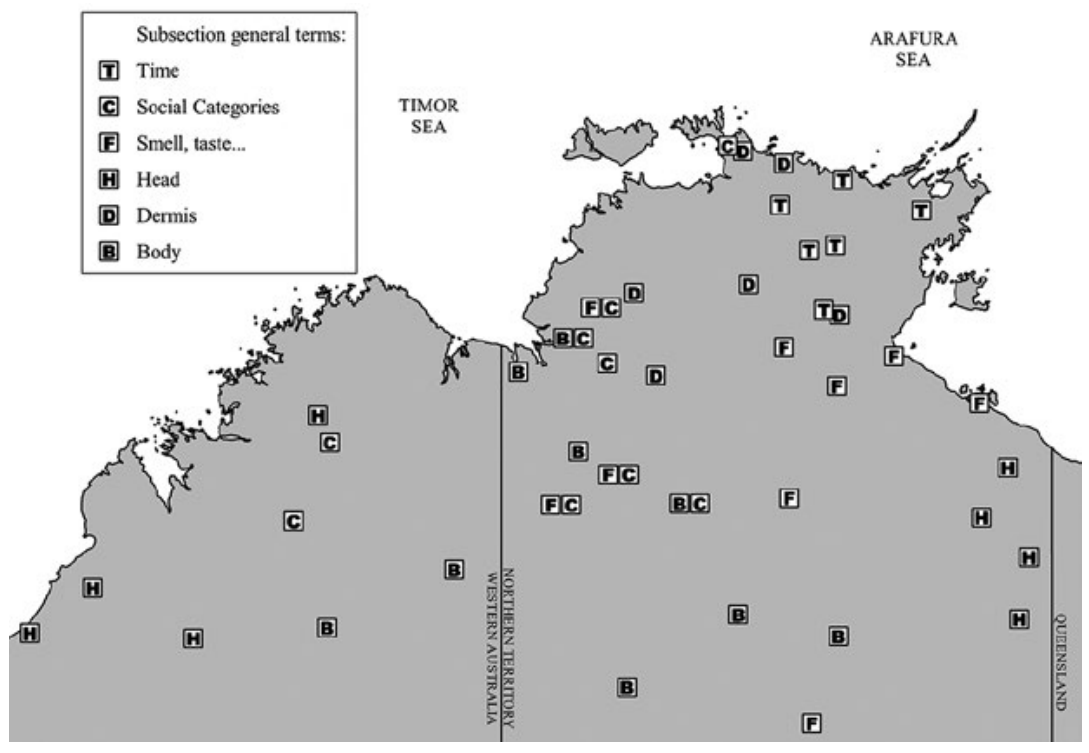

Figure 33: Map of geographical distribution of subsection colexification. Source: William McConvell. 
In the following section, we present each of the semantic clusters highlighted on the maps. We discuss our hypotheses regarding their semantic extensions and motivations, as well as their geographical distribution.

It appears immediately that the colexifications of the terms for 'subsection' mostly relate to the person and personal identity. The semantic range of these colexifications recalls the semantic network of Australian words for 'person' that was studied by Evans and Wilkins (2001). This work demonstrated the close semantic association between physical and social aspects of the person-an association also at play in the semantic network around generic terms for subsection (which partly overlaps the one for 'person'). In the following subsections, we discuss the motivations and articulate hypotheses for these colexifications.

In the first cluster of colexifications, subsection is colexified with other social categories. We hypothesise that a large number of other colexifications of generic terms for subsections could have gone 'through' the 'subsection/other social category' colexification. This hypothesis is represented on the semantic map (see Figure 32) by the fact that it is often necessary to go 'through' a 'social category' cell in order to reach the cells in other clusters. This aspect of the structure of the map results from the fact that for several clusters, there exists at least one language in which a tripartite colexification of the type 'subsection/other social category/member of the cluster' can be observed. In addition, many of these colexifications occur near the region where subsections originated as an institution, and several of them involve totemic social groups, such as groups emblematically represented by an animal. This hypothesis has consequences for mechanisms of semantic extension, as well as for the history of subsections (see the section 'History'). Further, colexifications involving distinctive aspects of the person such as 'dermis' may perhaps also relate to distinctive aspects of the totem (see section 'Physical Characteristics of Totem Animals').

The following sections discuss the other clusters. Colexifications involving distinctive aspects of the person such as the skin, smell and body are grouped together. This section opens with a discussion of the nature of chains of semantic associations leading to 'subsection/distinctive aspects of the person' colexifications. There are two plausible scenarios: first, these colexifications relate to distinctive features of the members of a social category (see the section 'Direct Associations between Social Categories and 
Physical and Mental Characteristics'); second, these colexifications relate to distinctive features of the totem animal linked to the subsection or a previous social category system in the region in question (see the section 'Physical Characteristics of Totem Animals'). It may also be that in some places, there is a trinity of links between person characteristics, totem characteristics and social category. In this section, distinctive aspects of the person clusters are discussed one by one: 'dermis', 'smell and flavour', 'body', 'head', 'name' and, very briefly, 'shadow'. 'Country and times' present a cluster involving colexifications that are not distinctive aspects of the person.

\section{Other Social Categories}

These are colexifications with terms for other social groups such as matrimoieties and patrimoieties, as in the languages of the Victoria River District, whereby the word ngurlu means both 'subsection' and 'matri-totem categories' (among other senses). These colexifications have been discussed by Evans and Wilkins (2001) and their motivation is straightforward. Subsections are relatively recent social categories. When they appeared, they had to be named. In such a situation, extending the meaning of a preexisting social category to cover the sense 'subsection' is a natural process. ${ }^{5}$ The social category colexifications and the other colexifications described in the following paragraphs are not mutually exclusive. Rather, as evident in Figure 34, for three of the most extensive clusters of colexifications identified (namely the 'dermis', 'smell and flavour' and, to a minor extent, 'head' cluster), at least one element of the cluster takes part in a threefold colexification of the type 'subsections/other social category/element of the cluster'. In addition, these colexifications with social categories occur in languages located near the region where the subsections system originated (see the section 'Subsections' and McConvell 1985a). It is thus possible to hypothesise that a significant number of colexifications of subsectionsnamely the ones in the 'dermis' and 'smell and flavour' clusters, and possibly some in the 'head' cluster-derive from initial colexifications of subsections with another social category.

5 Sections (the fourfold division) predated and were replaced by subsections in at least part of the area now occupied by subsections. This transition needs more research, and while there are a few clear examples whereby subsections replaced sections in the twentieth century (Western Kimberley, eastern Gulf of Carpentaria and Arandic in Central Australia), it is not patently clear that the generic term for 'section' was taken over by subsections. 


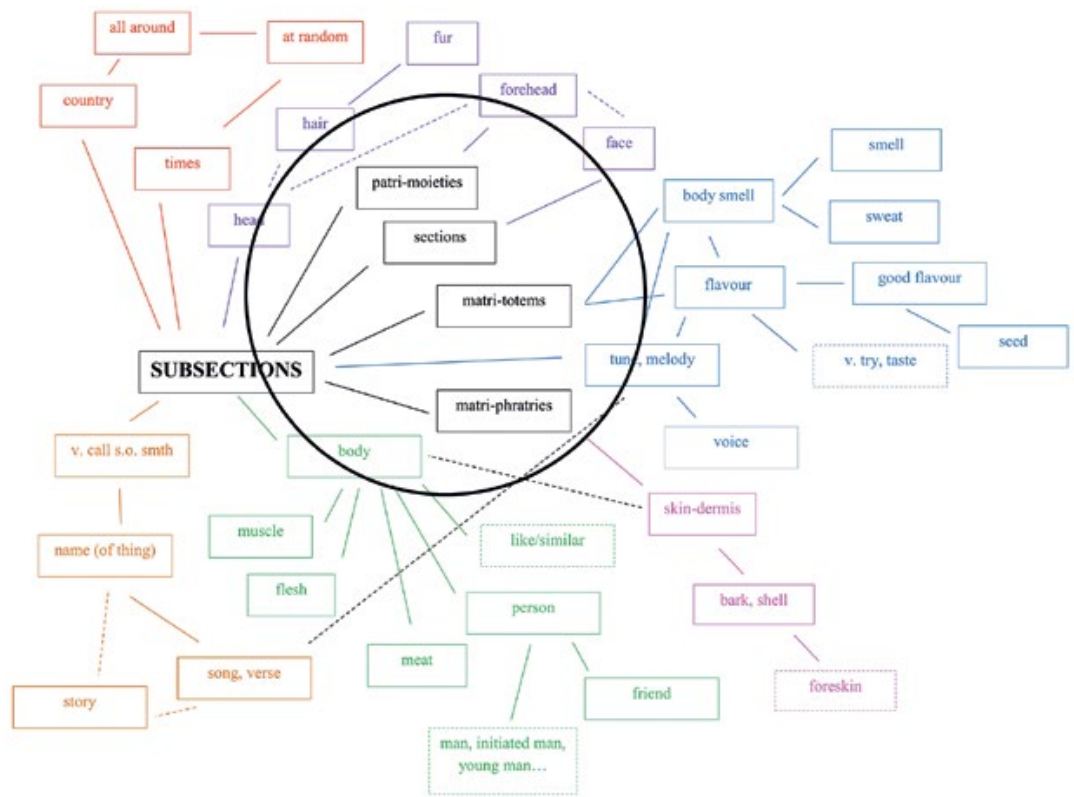

Figure 34: Position of 'other social categories' in the 'subsection' semantic network.

Source: Authors' work.

\section{Distinctive Aspects of the Person}

A large proportion of the colexifications of subsections have to do with the body and other aspects of the person that are all distinctive features likely to reveal and represent a person's identity: dermis, smell, voice, flesh, and body parts such as head, face and forehead (see Figure 32). These semantic associations between aspects of the body and subsection categories confirm Evans and Wilkins's (2001, p. 496) observation that "'body", "person" and "social identity" are intimately linked in semantic associations'. The concept of person may appear to constitute a natural conceptual 'bridge' between the notion of social category and physical appearance. This suggests that words for 'person' colexify with subsection, and also with 'body' and various aspects of the person (such as body, dermis and smell). If this is the case, a large number of languages should display threefold polysemies of the type 'person/subsection/distinctive aspect of the person'. However, as pointed out by Evans and Wilkins (2001, p. 505), such threefold colexifications are rare. Instead, we find many twofold colexifications of the type 'subsection/distinctive aspect of the person'. Hence, the representations in Figure 35 are incorrect, because 
subsections and features of the person should connect directly, as they do on the map of the general network in Figure 32 and in the adequate representation in Figure 36.

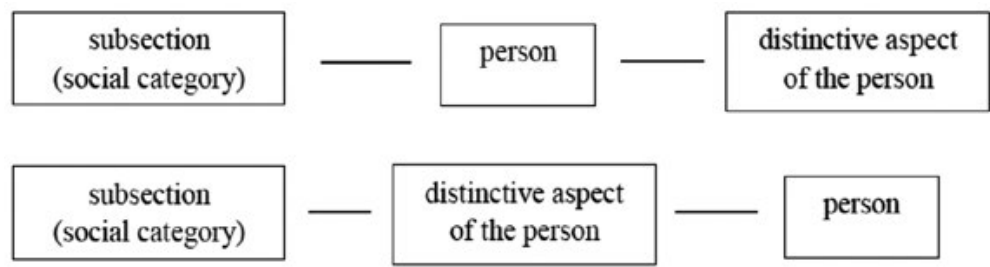

Figure 35: Inadequate (top) and supported (bottom) representation of 'subsection/distinctive aspect of the person/person' colexifications.

Source: Authors' work.

Evans and Wilkins's explanation for the frequent colexifications between social categories (which include subsections) and various aspects of the person is that speakers associate these concepts spontaneously. In their framework-which we endorse-colexifications (or polysemies in their terms) are evidence of conceptual association (see also Evans \& Wilkins 2000; Sweetser 1990). More specifically, the conceptual association between social categories and aspects of the person is metonymic, with a distinctive aspect of members standing for the set. ${ }^{6}$ In the section 'Direct Associations between Social Categories and Physical and Mental Characteristics', we discuss an alternative hypothesis-namely, that the metonymy associates the group label with distinctive aspects of the animal totem that represents a group, rather than distinctive aspects of members of the group. This hypothesis is attractive but not well supported by the data currently available.

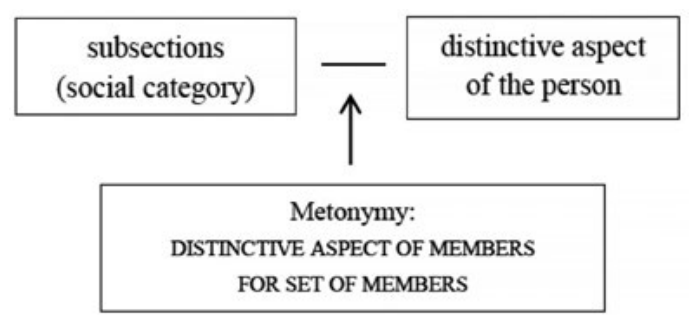

Figure 36: Conceptual explanation for 'subsection/distinctive aspect of the person' colexifications.

Source: Authors' work.

6 This metonymy may be further analysed as 'distinctive feature for member plus member for set'. 
In the following sections, we discuss each of the 'distinctive aspects of the person' clusters in more detail, starting with the most widespread and semantically consistent clusters ('dermis', 'smell and flavour' and 'body'), before moving on to clusters that display less consistency ('head'), are less widespread ('name') or for which the data are evanescent ('shadow').

\section{Dermis}

Colexifications with 'dermis' or related senses are found for instance in Iwaidja (Croker Island) where -ngurlhi means 'subsection' and 'dermis'. The Iwaidja -ngurlhi displays a threefold colexification of the type 'subsection/totemic social category/dermis' and, more specifically, 'subsection/matri-phratries/dermis' (with matriphratries being a totemic social category). It is therefore plausible that the 'subsection/dermis' colexification was mediated by the 'subsection/matriphratries' and the 'matriphratries/dermis' colexifications.

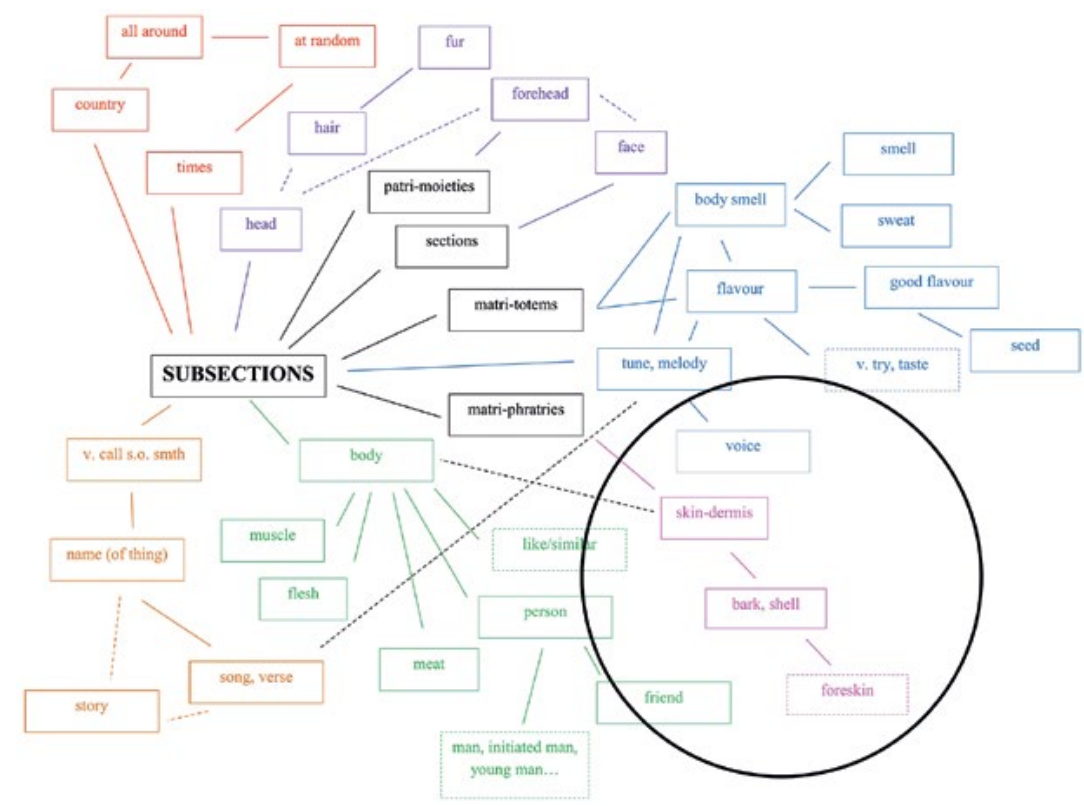

Figure 37: The 'dermis' colexification cluster.

Source: Authors' work.

Apart from dermis, the main colexification in this cluster is other types of outer covering in the natural world, such as bark and shell. This results from a standard polysemy between dermis, bark and shell, which is found in many Australian languages. A link between 'dermis' and 'body' 
as a whole seems plausible. Although the 'dermis/body' colexification is not attested in the sample, it is found in other languages in the world, including a few Australian languages (Western Desert languages; Wilkins 1996, pp. 285-7). This may create a link with the body cluster. ${ }^{7}$

As previously explained, the 'subsection/dermis' colexification is also exemplified in Kriol, Pidgin and Aboriginal English, and mainstream English. The section "Skin" Enters English' discusses our best hypothesis in respect to where this colexification was borrowed into these 'new' languages. Geographically, the distribution of this colexification is apparently continuous, extending between the Victoria River District (Wardaman) and the Cobourg Peninsula (Iwaijan languages), via the western Arnhem Land (central Gunwinyguan languages).

\section{Smell and Flavour}

Colexifications with 'smell' or related senses are represented by blue dots on the geographic map (see Figure 38). This colexification is well instantiated in Yanyuwa (towards the eastern edge of the subsection area, on the Gulf of Carpentaria) where ngalki means 'scent, odour, perfume, taste', as well as 'subsection' (and other related senses). 'Smell' colexifications prominently involve the notion of 'sweat smell' or distinctive body odour, as well as the notion of 'flavour'. In some languages, the same word also means 'odour' or 'scent' in general, and 'odour' and 'flavour' are colexified in some.

Kirton and Timothy's (1977) discussion of the senses of ngalki, the Yanyuwa term for subsections, offers some clues to understanding this colexification. The word means 'smell, voice, tune, subsection', and the authors argued for a monosemous interpretation of the cluster, with 'essence' as a common core. This formulation may be improved if we replace 'essence' by 'distinctive aspect/property'. Kirton and Timothy (1977) listed the following senses for the Yanyuwa word ngalki: subsections for humans and some other animates, the sweat of armpit for humans, the smell or taste of food, the perfume of a flower and the tune of a song (a further extension is found in the neighbouring Marra language, where the reduplicated form ngalkingalki means 'subsection' and 'voice'-another distinctive aspect of the person). While it is clear

7 This colexification is found in Papuan or Papuan-influenced Pacific indigenous languages including Pacific pidgin - for example, Takia (Austronesian) tini; Waskia (Papuan) kumik 'his/her/its body, skin, bark, surface' (Ross 2007, p. 121) and Tok Pisin skin 'skin, body, shell'. 
how the term 'essence' relates to this list, it also seems that each of its items are 'distinctive features' or 'distinctive aspects' of the thing in question. Among Aboriginal groups, humans' armpit sweat (i.e. flavour-smell) is distinctive of one's identity. For instance, someone visiting an important site should put their hands under their armpit to collect sweat and lay their hand somewhere (e.g. on a rock), in order to signal their presence to the spirits. Hence, body smell is a token for identity and a distinctive aspect of the person. Since the nature of 'essence' is unclear, and its relation to distinctive features a matter of unresolved philosophical debate, it seems preferable to avoid this gloss, and replace it with 'distinctive feature' or 'distinctive aspect'.

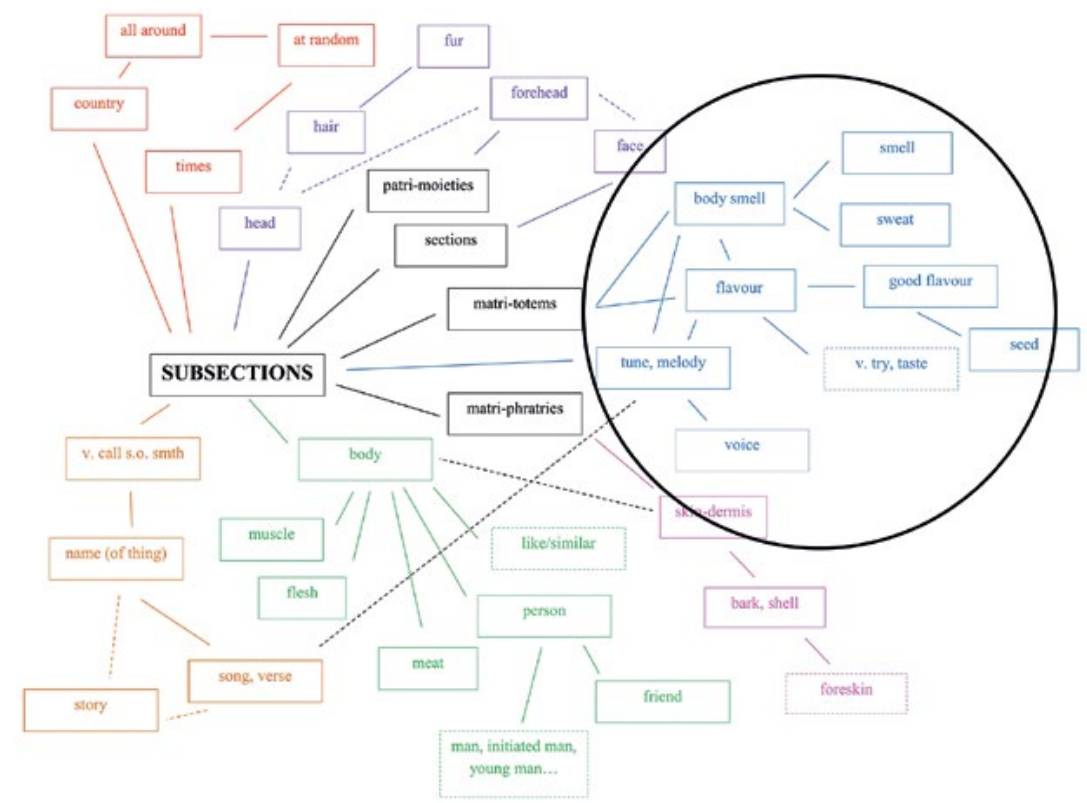

Figure 38: The 'smell/taste' colexification cluster.

Source: Authors' work.

In eastern Ngumpin languages, the form encapsulating the 'subsection/ matri-totem/flavour' colexification is ngurlu. This word is found throughout the Victoria River District in Ngumpin languages, meaning primarily matrilineal totemic clans, and secondarily subsections, probably indicating that the name was transferred from the former to the latter institution when subsections diffused into this area. It is also used in some neighbouring Non-Pama-Nyungan languages to the north for both 
institutions, where both forms of social category are recognised. It is used among groups, for subsections only, where matrilineal clans are not used, such as in the north-east Kimberley (Jarragan languages). ${ }^{8}$

The 'flavour and smell' cluster has further ramifications. At least one of the 'flavour' words in eastern Ngumpin, ngurlu, has a number of less expected colexifications, such as 'attractive' and 'seed'. Presumably, the first of these has something in common with expressions like 'good taste' (an attested extension of 'taste') and 'tasty' when applied in contexts unrelated to food, whereas 'seeds' are the edible and tasty parts of cereal grasses that were a staple in this area. In Jingulu, the term for subsection is colexified with a nominal manyku-probably related to the verb manyk'try, taste', with the 'smell' sense absent. Interestingly, the suffix used with masculine subsection terms in Jingulu is homophonic with, and perhaps etymologically related to, the Jingulu word for 'seed' nginju. This recalls the 'subsection/seed' colexification encapsulated by ngurlu in eastern Ngumpin.

The 'flavour and smell' cluster of colexifications with subsection is geographically widespread. It is found across a number of Non-PamaNyungan families in the western Gulf of Carpentaria, Barkly Tableland and some of the Arandic languages of Central Australia. Due to a lack of data on generic names of subsections for some languages, it is not certain that this is a continuous distribution, but this has not been ruled out. The Arandic languages have a closely similar set of senses to the one found in Yanyuwa (the set of 'distinctive features' discussed above). These languages colexify 'smell' and 'taste', as well as 'subsection' and 'section', so this could be an areal feature, despite the distance involved. Anmatyerr arreyn/arreytn (eastern) and arreny (western) also colexify 'subsection' with 'song, verse, tune' (reminiscent of the Yanyuwa association with 'tune'), albeit with a different word. There is no Arandic word with a threefold colexification 'subsection/smell, flavour/tune'.

8 There is a superficial similarity between the form ngurlu 'seed, flavour, matrilineal totem, subsection', which appears to have been inherited first in the Ngumpin-Yapa subgroup of PamaNyungan, and the terms for matrilineal 'totem, subsection' in Iwaidjan (ngurlhi, ngiri) in which the colexification is with 'skin, bark'. The Kunwinyku/Mayali form kurlah 'skin' could be related to Iwaidjan ngurlhi, since the third singular possessed form in Iwaidja is kurlhi. 


\section{Body}

Our data do not feature any threefold 'subsection/other social category/ body' colexifications, but include a threefold 'subsection/body/person' colexification (see Figure 39). The words that mean 'subsection' and 'body' can also mean 'meat, flesh' and 'muscle'. In some readings, the latter is synonymous with 'flesh', but also has a distinct meaning of a bulge of muscle, viewed externally and as a more localised instantiation of that 'calf-muscle' and 'calf' in general in Jaru (Wrigley 1992, p. 16). Another sense in the cluster related to 'body' is the property attribute of a person or animal in good condition as opposed to too thin-also an expected extension of 'body' (Evans \& Wilkins 2001, p. 504).

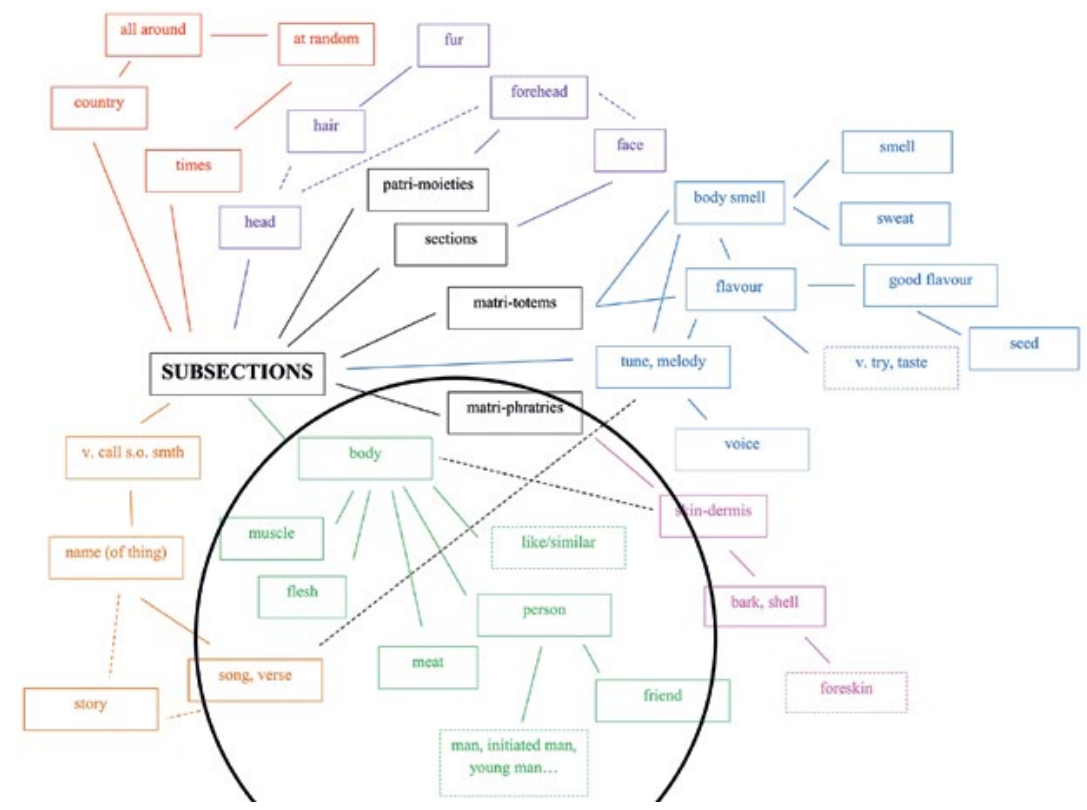

Figure 39: The 'body' colexification cluster.

Source: Authors' work.

The cluster also includes the sense 'person'. The body/person colexification is quite widespread in a number of Australian language groups, especially in Central Australia and in languages to the north-west. This colexification has been explored by Evans and Wilkins (2001) and is found in languages in different parts of the world, including English 'somebody'. In the area of Australia we are focusing on, strict colexification of person and body is found in parts of the Western Desert-for instance, yarnangularnangu 
in the southern Western Desert. In spite of the frequency of the twofold 'body/person' colexification, our language set contains only one example of a triple colexification 'subsection/body/person' (tyerrtye in Arrernte). There is also only one case of loose colexification, with the 'person' word puntu. Evans and Wilkins (2001, p. 499) reported that puntu means 'subsection' in Warlpiri, where it also means 'friend, companion'. Puntu means 'person' and 'body' respectively in some other languages, but not in Warlpiri.'

The 'like, similar' meaning of 'body' is also cross-linguistically common and is found in the Daly area (nginipunh, Murrinhpatha). It is classed as 'loose', since the form meaning 'like, similar' is no longer a noun, but has become grammaticalised as a suffix. Thus, the relationship with the homophonous noun meaning 'subsection' and 'body' is etymological. Another word that colexifies 'body' and 'subsection' in the northern Victoria River District Ngumpin languages, mayi, is found in another Ngumpin language Wanyjirra (Chikako Senge pers. comm.), some distance away, as a 'like, similar' suffix.

In terms of geographical distribution, the 'subsection/body' colexification is found to the west of the subsection distribution, mainly in Ngumpin languages (Pama-Nyungan), but also in Murrinhpatha, a neighbouring Non-Pama-Nyungan language to the north. This colexification is exemplified by a range of diverse forms. In Ngarinyman and Mudburra, in eastern Ngumpin (Pama-Nyungan) in the Victoria River District, the form that colexifies 'subsection' and 'body' is mayi. In the northern neighbouring western Mirndi languages, the form mayi means 'body', but not 'subsection'. In western Ngumpin, the same 'body/subsection' colexification is found. In Jaru, the term buya meaning 'body', 'flesh' and 'muscle' is used for 'subsection' (Wrigley 1992, p. 16), and in Walmajarri the term ngilyki 'flesh' also means 'subsection' (Richards \& Hudson 1990, p. 190). In Gajirrabeng, a northern Jarragan language in the east Kimberley, the term for subsection is not the same as 'body' but is derived from it, albeit by a morphological process that is not fully understood. In this instance, the 'body' word (juwugeng) is also colexified with 'person' - a kind of polysemy known elsewhere.

9 Whether this results from some kind of constraint or is accidental is not clear. See the next section for further historical interpretation. 


\section{Head}

Another cluster of colexifications, represented by purple dots on the map (see Figure 40), concerns body parts around the head. This includes 'head', 'face', 'forehead' and 'hair' (and 'fur' as an extension of words meaning 'hair'). This colexification is found, for instance, in Ungarinyin (Kimberley) where amalarr means both 'subsection' and 'forehead' (as well as 'moiety'). The head and its attributes, especially the face, are also very distinctive of individual identity (Evans \& Wilkins 2001; Ponsonnet 2009). A particularity of this cluster is that it is geographically discontinuous. Colexifications involving face and forehead are found in the north-west of the subsection area, and are actually more frequent for sections than subsections; colexifications involving the head and hair are found in the south-east of the subsection area, around the middle of the Gulf of Carpentaria on the Queensland coast.

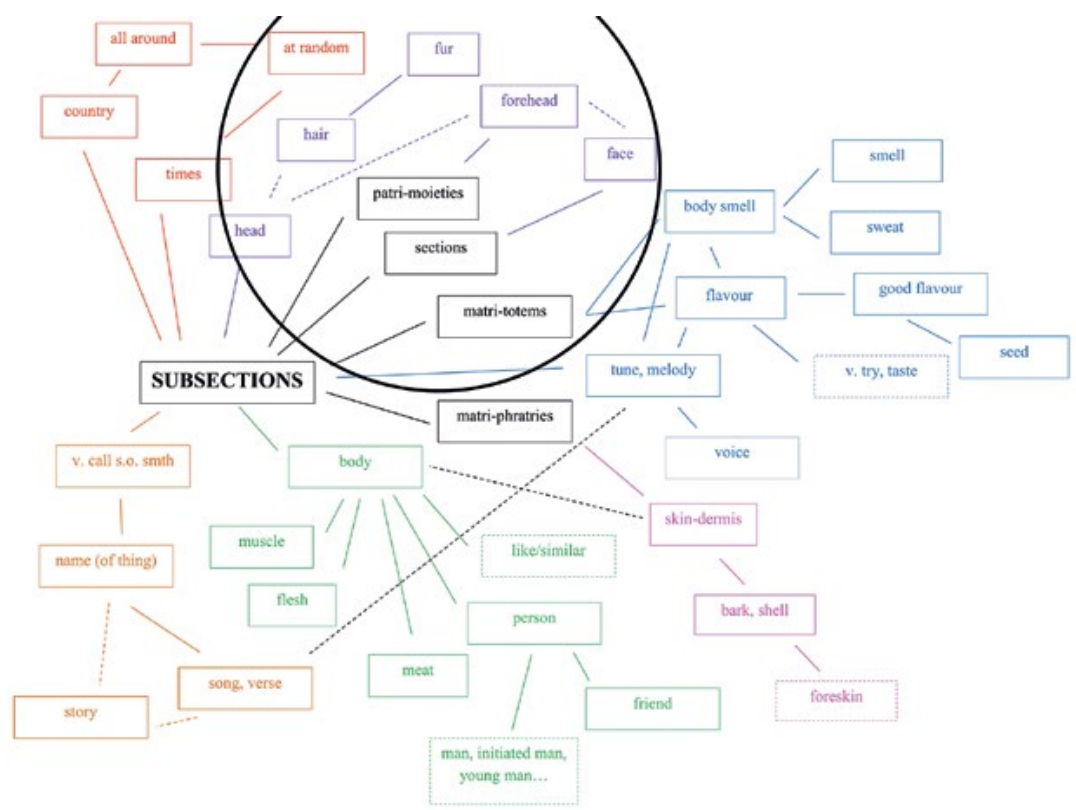

Figure 40: The 'head' colexification cluster.

Source: Authors' work.

Threefold colexifications involving 'subsection/other social category/ attribute of the head' are found with 'forehead' and 'patri-moieties' and with 'face' and 'sections' at the eastern edge of the subsection area. Terms for 'face, forehead' (miparr, ngumpa) are used for sections in the Marrngu languages of the south-western Kimberley and eastern Pilbara. 
In Ungarinyin, a Worrorran language in the central Kimberley where subsections are only marginally used, the colexification of 'forehead' with generic patrilineal moiety has been extended to subsections.

'Head' and 'hair' are found as colexifications of 'subsection' on the opposite side of the subsection area, in the extreme east of the expansion of subsections in the Tangkic family of languages on the Gulf of Carpentaria coast and islands. 'Head' and 'hair' are occasionally found colexified in Australian languages, but not in Tangkic (at least not in recent times) where there are two separate items that are both colexified with 'subsection'. The colexification of 'hair/fur' and '(sub)section' is found far south in lower Arrernte. For concepts of types of hair in relation to social categories, see the section 'History'. Threefold colexifications involving 'subsection/other social category/head or hair' are absent in our data. Hence, head-related colexifications (with hair [fur], face and forehead) are recurrent in the data, but are scattered on each side of the continent, and thus form a less consistent cluster.

\section{Name}

Colexifications with 'name' and related senses are represented by orange dots on the map (see Figure 41), and occur only in a few languages at the extreme south of the subsection area. This small cluster relates to a more literal way of expressing the function of subsection terms. Some languages do not have a colexification of the same kind that we have been discussing - that is, based on a noun. To enquire about someone's subsection, one asks, 'What are you called?' or 'What is your name?' These expressions are vague and do not specifically refer to subsections. However, forms derived from 'calling by name' have become specific to talking about subsections and sections as in western Arrernte and Anmatyerr. Again, a name is obviously a distinctive aspect of the person; however, this time, the colexification does not result from metonymies involving aspects of the person, but simply from a pragmatic bridging context in which the more generic concept of name is used to enquire about the more specific category of subsection. In Anmatyerre, the form arreyn/arreytn (eastern) and arreny (western) colexify 'subsection', 'name' and 'song, verse or tune'. This recalls the sense of 'tune' colexified with 'smell and flavour' by the word ngalki in Yanyuwa, much farther to the north-east. Again, songs usually relate to social categories and personal identity and may be treated as tokens of identity. 


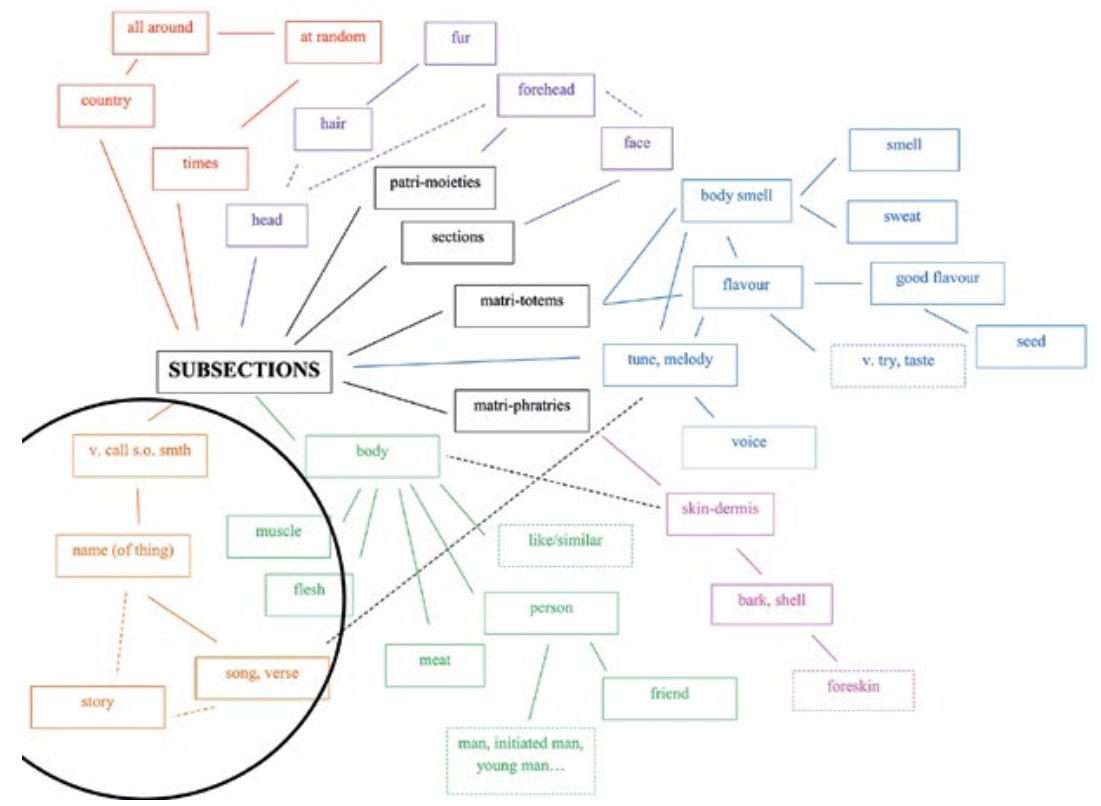

Figure 41: The 'name' colexification cluster.

Source: Authors' work.

\section{Shadow}

In the Bunuban languages, the term for subsection, kuru, is also extended from patrilineal moieties. It is possibly related to the word for 'shadow, shade' kururru, but the derivational mechanism is unclear. ${ }^{10}$ Semantically, there is often colexification in Australian languages between 'shadow' and 'reflection, image', which is plausibly related to the identity aspect of social category membership. There are other connections between social categories and types of shade in other regions-for instance, in the Western Desert and northern New South Wales/southern Queensland.

\section{Country and Times}

This cluster of colexifications is represented by red dots on the geographic map (see Figure 42). It occurs in a discrete region to the east of the Top End, in central and eastern Arnhem Land, adjacent to the area where 'dermis'

10 In Jaru and eastern Walmajarri kurukuru is 'black' - the etymology could be 'like shadow (dark)'. Kuru is 'eye' in Western Desert language and there are cognates in a number of western PamaNyungan languages with sound changes pointing to the relatively great age of the root (McConvell \& Laughren 2004). Since 'eye', 'face' and 'forehead' are commonly colexified, it is possible that the Bunuban subsection generic is a 'loose' (historical) colexification of the 'head' set. 
colexifications are found. For example, in Dalabon (Gunwinyguan, Arnhem Land), the noun malk means both 'subsection' and 'weather, season'. This set of colexifications is rather different from the others and its internal semantic connections are puzzling. In various Gunwinyguan languages (Arnhem Land) and in the neighbouring Burrarra, the form malk is found to colexify 'subsection' and the senses 'at times', 'all around', 'at random', 'weather/season' and 'country' (however, no language has all colexifications). In addition, among the Gunwinyguan languages, Kuninjku uses the form kurn for subsection, which is cognate with Dalabon kurnh, meaning 'place', for instance.

In some Bininj Gun-wok dialects, the form malk also means 'liver'. However, 'liver' is marlk in Dalabon, with a retroflex lateral. In addition, neither the sense 'liver' nor any closely related sense (e.g. abdominal part) are colexified with 'subsection' anywhere else. The presence of the retroflex and the absence of attested semantic associations suggest that the colexification of 'subsection' and 'liver' in Bininj Gun-wok results from homonymy.

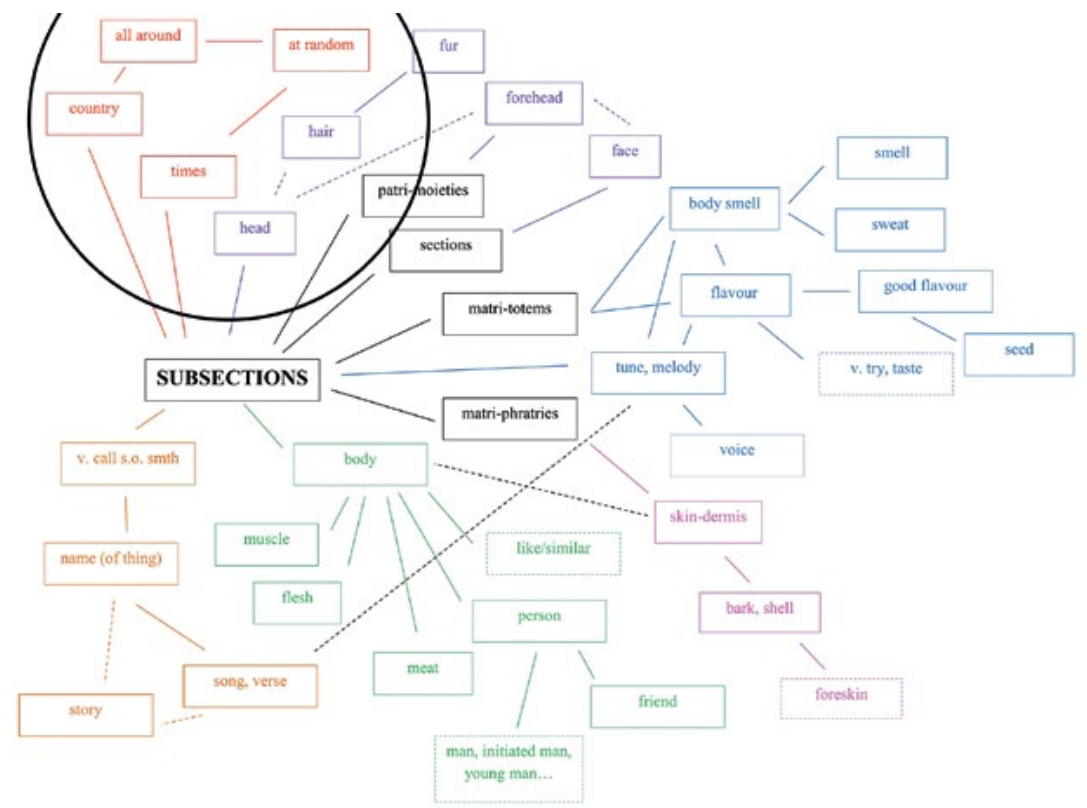

Figure 42: The 'country and times' colexification cluster.

Source: Authors' work. 
It is not impossible that the colexification between 'subsection' and 'at times', 'all around', 'at random', 'weather/season' and 'country' also results from homonymy. Indeed, in Yolngu, 'subsection' is maalk and 'at times' is malk. Since the Gunwinyguan languages do not use a vowel length distinction, the Yolngu maalk could have been borrowed as malk from neighbouring Non-Pama-Nyunguan languages, resulting in homonymy with another lexeme malk, meaning 'at times'. However, the existence of an independent (loose) colexification of 'subsection' and 'country', with the Kuninjku kurn (cognate with Dalabon kurnh, 'place'), suggests that the conceptual association, even if it resulted from homonymy originally, would have been reanalysed as a polysemy at some point.

In spite of this possibility that the colexification between 'subsection' and 'at times', 'all around', 'at random', 'weather/season' and 'country' may result from homonymy, it is also worth considering the hypothesis that it is inherently a polysemy. The conceptual associations between these senses are puzzling, but not implausible. Apart from 'subsection', the most widespread sense of malk, and thus its probable oldest known sense, is 'at times'. Several paths of semantic associations between this sense and the others-'at random', 'all around', 'weather/season' and 'country'seem plausible.

Saulwick's (2003) Rembarrnga dictionary indicates a bridging context in which the adverb malk could mean 'at times', 'at random' and 'all around': malk is used to describe someone 'shooting at random in the air'. Shooting at random is likely to involve shooting several times and all around. This would explain how the older meaning 'at times' could extend to 'all around'. In Dalabon, malk is used in compounds meaning 'look all around' (malk-nan, nan 'see/look'), which suggests an extension to 'country'. It is typically the country that one looks at when 'looking around'; therefore, this Dalabon compound also offers a bridging context for the extension from the sense 'all around' to the sense 'country'. The association with 'weather/season' or 'season' may relate to the fact that these are also descriptions of the environment or surroundings.

These semantic associations can also be presented from a different angle. The connection between country or place and time has been reported by Evans (1992a). For instance, an association between 'country' and 'times' (as in 'a number of times') is suggested by the Warlpiri word ngurra, which means a camp (i.e. a place, that can further extend to 'country'), but also a night spent at a given camp, where places correspond to successive 
stopovers along an itinerary (Musharbash 2008, p. 34). The Gurindji cognate is used in expressions such as ngurra kujarra 'two camps, two nights', in which place and time units are conceptually merged. The sense 'all around' could also derive from the same concept of cyclic itinerary (a series of 'camps' or stopovers along a journey). In addition, the notion of stopovers on a cyclic itinerary could also explain the extension 'weather/ season'. With this scenario of semantic extension, the sense 'subsection' could also relate to the 'stages of a cycle' (this time, a cycle of successive generations), similar to 'weather/season'. While this scenario is not implausible, it is highly speculative and there is little evidence to support it. The previous scenario (based on contexts such as 'to look all around' and 'to shoot at random') is better supported by actual bridging contexts in Rembarrnga and Dalabon.

In the scenario presented in Figure 43, whereby 'at times' connects to 'country' via 'at random' and 'all around', it is not entirely obvious how this colexification set relates conceptually to 'subsection'. A possible link may be via the notion of totemic site (place and country). Bininj Gun-wok dialects have malng, meaning 'clan spirit which returns to a deceased's country after death', which could plausibly be cognate with malk, and could therefore support this conceptual path. While the $k>\eta$ sound change is not straightforward and not clearly attested among the Gunwinyguan family, it is rendered more plausible by an environment in which the word occurs frequently in the Bininj Gun-wok dialect Kune (which is very close to Dalabon, both geographically and linguistically). As Kune has obligatory suffixes on some nominal subclasses (Evans 2003; Ponsonnet in prep.), the default form of the word malng in this dialect is malng-no. In this default environment, the first consonant of the suffix explains the shift to a nasal as backwards assimilation. Seen as a reference to personal totemic birth site, the 'subsection/country' colexification reconnects with the aspect of the person or totem clusters.

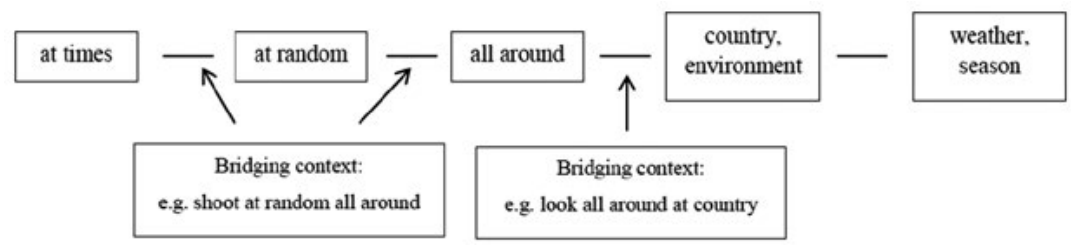

Figure 43: Suggested chain of motivations for 'at times/country' colexifications.

Source: Authors' work. 
Another puzzling feature in this cluster is that in Ngalakgan, the form malk is also reported to colexify the sense 'dermis', linking the 'country/ times' cluster to the 'dermis' cluster. Conceptual associations between 'dermis' and the 'at times' cluster ('all around', 'at random', 'weather/ season' and 'country') are relatively loose. ${ }^{11}$ Since in varieties of Kriol or Aboriginal English, the form skin is broadly used for both 'subsection' and 'dermis', it is not impossible that speakers have imposed 'dermis' back translations on words for subsections that did not originally mean 'dermis' (in fact, such back translations from 'subsection' to 'dermis' are confirmed for Arrernte).

\section{Generic Terms and Ethnotheories of the Body and Personal Identity}

\section{Direct Associations between Social Categories and Physical and Mental Characteristics}

A number of concepts that are used as generic terms for subsections also play a part in Aboriginal ethnotheories of social categories that include subsections. For instance, the concept 'dermis' came into English as the word skin, meaning subsection. In some places, the colour of people's skins (dermis) is supposed by local Aboriginal people to be associated with certain subsections. Similarly, 'hair' is used as a generic term for subsection in the east and south of subsection distribution, and in some places the type of hair (straight/curly) is said to be associated with subsections. It should be noted that Aboriginal people do not, so far as is known, make a conscious association between generic terms and these ethnophysiological ideologies, nor is there any good fit between the languages that have particular generic terms and particular ideologies. For instance, it is not reported that people say, 'We call subsection "dermis" because it reflects differences in our skin colour'.

11 It was suggested to us that the dermis is 'all around' the body. However, this is not very convincing, especially since in Ngalagkan, only the sense 'at times' is reported, not 'all around', which is probably derived from 'at times'. Also, the 'dermis' is 'all around' the body in a way that does not match occurrences of this sense in the cluster in which 'all around' refers to the whole environment rather than a thin envelope. 
One researcher who made a great deal of such associations and other associations related to characteristics of body shape and mental disposition is von Brandenstein. After initially developing his approach with sections, he later moved on to write a book about subsections. The work by von Brandenstein (1982) was received with great scepticism by most, but praised by some. McConvell's (1985b) review article is highly critical of von Brandenstein's methods and results. One of von Brandenstein's (1982, p. 5) methodological principles proposed that:

If a superstructure of the highest philosophical order is found to have existed in one Australian region and to have ruled a particular sociocultural practice there, it must also be involved in other regions where similar or identical sociocultural practices can be observed.

He continued on to suggest that the Dreaming ensured absence of change, and was wrongly interpreted by people using European notions of change, such as Testart (1978). The idea that high-order philosophical superstructure 'rules' practice is highly dubious. Leaving this aside, there is also the notion that the existence of a practice in one place implies that a superstructure or ideology found in that place 'is involved' in another place where the practice is also found, even if there is no evidence for the existence of the ideology. This is an absurd method that leads to the invention of all kinds of non-existent explanations.

A list was collected by von Brandenstein (1982, p. 6, see pp. 150-1 for notes and references) of what we are calling 'generic terms' for subsections and other social divisions, and their semantic associations. This list overlaps significantly with what we have already presented. It includes the following:

- flesh or meat

- body

- skin

- head

- forehead or face

- hair

- eyes

- side

- liver or temper

- colour 
- taste

- scent (armpit sweat)

- voice

- identifying essence

- half

- run or section

- mate or friend

- namesake.

The list is a mixture of generic terms for moieties, sections and subsections, and may also include totemic clans, with no apparent attempt to make historical or geographical sense of the distribution. The prime reference for 'taste' is Yanyula ngalgi (ngalki, Yanyuwa, Gulf of Carpentaria; Kirton \& Timothy 1977), which is also rendered as 'identifying essence' ('distinctive feature' in our terms). This is linked to an addendum discussing ngurlu 'matri-totems', 'flavour', 'seed' and 'good taste' (eastern Ngumpin, Victoria River District), which is apparently proposed as being related linguistically to ngalgi. Our preferred interpretation is that the colexification might have spread widely and subsequently been 'borrowed', but it is unlikely that the forms are cognates. The addendum contains a great deal of misleading information. The Dalabon subsection generic, citing Maddock (1969, pp. 37, 53), is said to be both dermis and liver/temper. According to our analysis, the latter is a confusion between the word malk and marlk.

Despite von Brandenstein's (1982) strictures on history, he did propose a hypothesis on the origin of subsections by way of adding a 'side set' of terms related to attributes of body and temperament to the previous sets in the section system. There does not seem to be any attempt in this book to link these attributes to the generic terms of sections or subsections. The history that von Brandenstein proposed is highly abstract and detached from the realities of the world and society. McConvell's (1985a) concrete and original hypothesis regarding the origin and diffusion of subsections also did not take into account the generic terms as part of the story. In his critique of von Brandenstein, McConvell (1985b, pp. 56-9) emphasised that beliefs about traits attributed to sections and subsections are not universally present in the areas where the social categories exist, and are not equally important nor consistent across different areas. However, the fact remains that there are a handful of generic names that are found for 
these systems that, although diverse, have certain similarities and perhaps relate to ethnophysiological and ethnopsychological aspects of the person. We have started the task of reconstructing the diffusion or inheritance of generic names and examining how this fits with the diffusion of the specific social category terminologies themselves. A further stage would be to match the history and geography of the ethnogenetic systems to the generic terminologies.

The core of the generic social category terms in their more concrete meanings seems to point to characteristics that identify individuals. The term 'individual essence' has been used; however, this might be adding a literal 'essentialist' slant and 'distinctive aspects'-including the dermis, smell and flavour, body, head and its attributes and namemight be preferred. As pointed out by Evans and Wilkins (2001), it is no coincidence that some of these senses have also come to mean 'person' in Australia and elsewhere. Aspects of the body that are particularly liable to being used for generic social category terms are those that are most apparent and specific to individuals. There is a semantic unity to these various complexes despite the fact that they have their own histories, and it makes sense to suggest that these colexifications reflect speakers' conceptual associations between distinctive aspects of the person and social category. From this perspective, it is interesting to note that von Brandenstein's (1982) theory is not entirely at odds with Evans and Wilkins's (2001) suggestions in relation to the Australian concept of 'person', as von Brandenstein's postulated beliefs are also related to the same fundamental attributes that identify individuals. Our preliminary study of the semantic network of the generic term for 'subsection' partly confirms Evans and Wilkins's (2001) suggestions.

\section{Physical Characteristics of Totem Animals}

Another hypothesis proposed to explain the colexification of 'subsection' with senses that denote aspects of the person is that colexifications may result from an association of social categories with aspects of totemic figures, such as the animals for which totems or 'dreamings' are identified, rather than with distinctive aspects of the person. Thus, this hypothesis is different from the one that von Brandenstein (1982) proposed. While there are associations between sections and aspects of personal identity for sections in some areas, this is very rare for subsections. 
The two scenarios-one involving conceptual association of social categories with distinctive aspects of its members, and the other relying upon distinctive aspects of the totem independent of aspects of the members - are not exclusive of each other. The former may apply for colexifications in some languages, and the latter with others. As previously mentioned, the scenario involving aspects of the totem rather than aspects of the person is not yet unambiguously supported by the data that we currently have in hand. Nevertheless, this scenario has one interesting advantage over the other: it is in line with the near-complete absence of folk theories that attribute distinctive physical features to people according to their subsection.

This hypothesis is further supported by the fact that some of the social categories in question-in particular, matri-totems in the Victoria River District and matriphratries among Iwaidja speakers-are associated with totemic emblems. Across the continent, totems are often animals, which may be referred to metonymically using some of their most salient features. Most Australian languages have a colexification of 'meat' and 'animal'; thus, in areas in which social categories such as totems or sections are called 'meat' in Aboriginal English and a 'meat' term in a local language, this can also be translated as 'animal'. In some areas where totems are animals, restrictions may be placed on the consumption of that particular animal. The cultural salience of totem consumption may justify metonymies whereby one's totem is designated as one's 'meat' or 'flavour'. For example, in Kayardild, the word wuranda colexifies the senses 'food', 'meat, flesh', 'totem' and 'kind' (Evans 1992b).

At this stage, the actual nature of totems in regions where 'subsection/ totemic social category' colexification is known to occur does not support this hypothesis particularly well. Our data feature several threefold colexifications involving subsections, totemic social groups and flavour or smell. We find 'subsection/semi-moieties/flavour-smell' in Yanyuwa, but also, close to the region where subsections originated, Ngan'gi (Daly family) has 'subsection/matri-totem/flavour-smell'. A bit further south, in eastern Ngumpin languages (which do not colexify flavour and smell), the colexification set includes flavour, but not smell ('subsection/ matri-totem/flavour'). Thus, the aspect-of-totem scenario, whereby 'subsection/aspect of person' colexifications obtain via metonymies involving aspects of the totem (here, flavour, naturally extending to smell by virtue of a widespread monosemy) and not of the person, is a plausible explanation for the colexifications in this cluster. 
In the case of Yanyuwa, it would seem that the generic term for subsection could apply both to the distinctive aspects of persons and those of totems. Based on Kirton and Timothy (1977), it appears that flavour and smell are core senses of the word ngalki (other distinctive features such as the melody for a tune being marginal). 'Flavour/smell' colexifications are common in Australian languages and probably correspond to a single concept in languages in which they apply. As previously explained, body smell is a token for human's identity (and for some animals). Further, ngalki also refers to the flavour(-smell) of an animal when it is eaten, and this could apply to an animal totem. Another sense of ngalki, 'tune of a song', may easily relate to totemic features, given that many local songs are totemic songs (i.e. they recount the journeys and adventures of ancestral beings). However, none of these social categories involve totemic figures; therefore, the aspect-of-totem scenario is less plausible for this cluster.

\section{History}

\section{The Diffusion of Subsections and Subsection Generic Terms}

As already mentioned, the relationship of different senses of lexical items is not purely synchronic but can involve change from one meaning to another, with an intermediate stage of polysemy/colexification. This stage is either discoverable in other languages as synchronic, or plausibly reconstructed by identifying one or several 'bridging contexts' in which sense ' $\mathrm{A}$ ' is ambiguous with sense ' $\mathrm{B}$ '.

These kinds of hypothesised historical change can be traced by anthropological modelling and from linguistic studies-particularly of the changes in individual subsection terms and their relationships with earlier systems such as sections (McConvell 1985a, 1997). The development of different generic terms for subsections can provide evidence that feeds into the hypotheses regarding the historical origin and spread of subsections (Evans \& Wilkins 2000).

The diffusion of subsections is known from historical distribution. However, evidence about the spread and change of subsections also constrains and moulds what we might conclude about the history of generic terms. Figure 44 is a rough map that shows the broad outline of the diffusion of subsections overlaid on the map of generic terms for 
subsections (see Figure 32). The remainder of this section briefly explains the history of subsections and how it fits within the history of generic terms, including how generic terms may add to our understanding of subsection diffusion. The section "'Skin" enters English' is a case study of a particular development in which the 'subsection/dermis' colexification spread to western Arnhem Land and incorporated into Aboriginal English, before spreading widely as the term 'skin'.

The subsection system is found in the central north of Australia. It does not extend to the north Kimberley or the central Top End of the Northern Territory around Darwin and the Tiwi Islands. The system was reported in the Daly River region in the mid-twentieth century (subsequently abandoned) and in eastern Arnhem Land, but it is clear from historical data that the system had only spread into these regions within the last 100 years. Subsections also recently spread into Central Australia, replacing the section system (see Chapter 10).

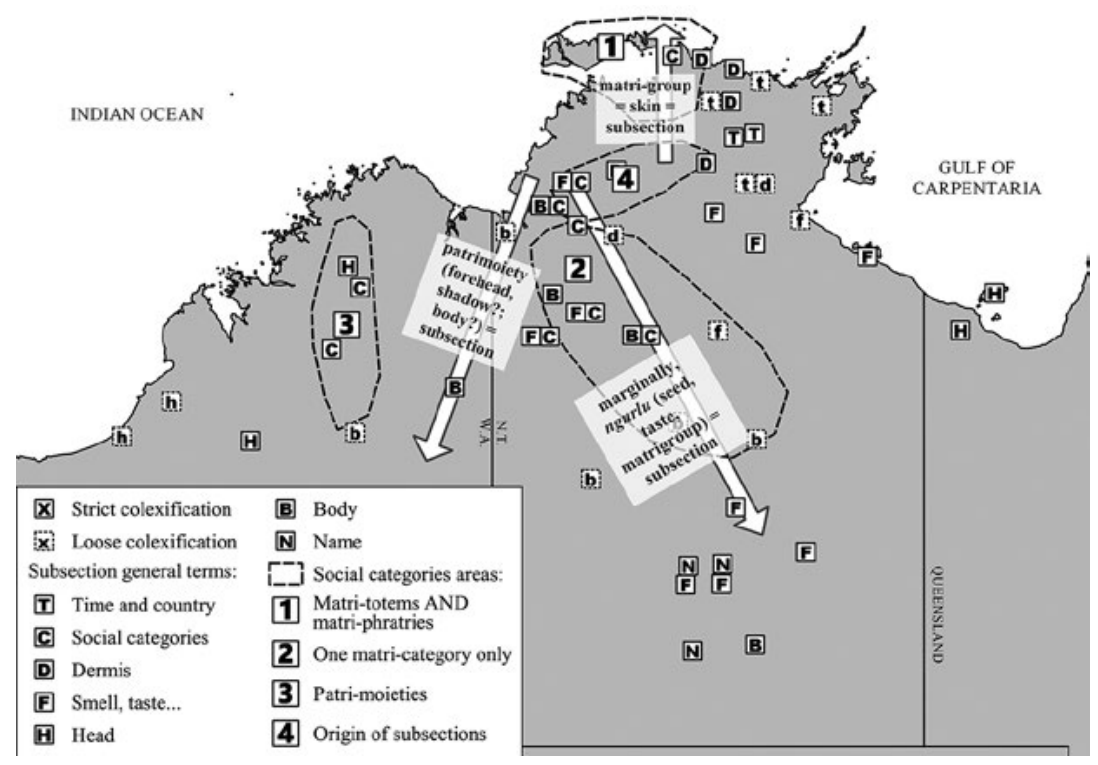

Figure 44: The historical spread of subsections and the generic terms. Source: William McConvell.

The subsection system emerged in the area around Katherine in the Northern Territory and diffused from there in several directions, replacing or adding to previous social category systems. This general hypothesis is supported by persuasive linguistic evidence (McConvell 1985a, 1997). 
While others (e.g. Harvey 2008; Chapter 10) have offered modifications of detail, this general hypothesis has not been strongly challenged. The hypothesis also includes a modelling of how the subsection system derived from the meeting up and interaction of two section systems - one from the west and one from the north. According to the hypothesis, this involved a particular kind of circular connubium (asymmetrical marriage between groups). We will not go into the details of this reconstructed history, but it does provide a background as to how we might view the distribution and history of the generic terms for subsections.

There were at least four main early pulses of diffusion (McConvell 1985a):

1. south-west through the east and central Kimberley

2. south into Central Australia

3. south-east to the Barkly Tableland and Gulf of Carpentaria

4. north-east into central western Arnhem Land.

All of these diffusions occurred in stages and had later extensionsincluding extensions within the last century-further into parts of eastern Arnhem Land and north-eastern Western Desert, as well as north into Daly River. In the next part, we comment on the generic terms for subsections that are related to each of these major diffusions.

\section{South-West Diffusion}

Two of the three Jarragan languages in the east Kimberley do not have generic terms for subsections but use a suffix for 'kind' (-nge-) on interrogatives relating to subsections and on the subsection term itself (e.g. jangala-ngeny 'Jangala kind'). The northernmost Jarragan language Gajirrabeng has a word for subsections derived from 'body' joowoondeng, and also uses the term ngoorloong, which is borrowed from eastern Ngumpin ngurlu. Since the latter has as its primary meaning 'matriclan' to the east, and matriclans are not part of the Jarragan culture, it is probably a relatively recent loan from the east in the meaning 'subsection'. However, the 'body' colexification does relate to others in the immediate area (northern east Ngumpin mayi and Daly River). 'Body' also continues to the south in the Kimberley with Jaru and Walmajarri. Therefore, it seems likely that the 'body' colexification had its origin in northern- 
eastern Ngumpin and spread with the south-west diffusion. The apparent absence of this colexification in two languages in the middle of this spread remains to be explained.

In the west Kimberley, Nyulnyulan languages sections related to those of the Pilbara are reported from the early to mid-twentieth century, although their role in social organisation was marginal. The generic terms for 'section' in the Pilbara and adjacent Western Desert also meant 'face' in the local languages (e.g. Nyangumarta ngumpa, Karajarri miparr), but 'face' for subsection is not reported in the west Kimberley. The term 'forehead' (amalarr) is used for generic subsection in the central Kimberley in the southern Worrorran language Ngarinyin, where subsection use was marginally encroaching, and 'forehead' and 'face' are commonly colexified. The origin of this is not necessarily the same as for the 'section/face' colexification in the Pilbara, since 'forehead' is a term for patrimoiety, an important institution in the central Kimberley, and it appears that as subsections moved out to the edge of their distribution, their generic names were equated with the locally important pre-existent social category. The same colexification 'subsection/patrimoiety' occurred in the Bunuban languages south of Worrorran; however, the term was not a 'forehead/face' term. In fact, the generic term for subsections in this language family (kuru) is not immediately interpretable. It could be related to 'shadow' (kururru) or perhaps the common word for 'eye' (kuru), which is commonly colexified with 'face'.

\section{Southern Diffusion}

According to McConvell (1985a), the southern diffusion of subsections started in western Mirndi (Jaminjungan) and neighbouring languages. It probably spread quite soon into the eastern Ngumpin languages to the south. Across this area, apart from the north where 'body' (mayi) is used, the only generic term for subsections, ngurlu, is also the term for matrilineal clan, another important institution that probably existed in the region before subsections originated and spread. In fact, ngurlu is not a particularly common designation for generic subsections in this area, and some people claim there is really no term for generic subsection. This is reminiscent of the apparent absence of a true term for generic subsection in western neighbours Miriwung and Kija, in the east Kimberley. Going further south to the Warlpiri, the term puntu for generic subsection, also meaning 'friend' or 'relative', also seems to be unique. The root is 
etymologically related to words for 'person' in other languages and from there to the meaning 'body'; however, this history is not retained in the Warlpiri meaning. ${ }^{12}$

South of Warlpiri, subsections spread into Arandic languages (see Chapter 10). The northern languages have colexification with 'body smell', and this is extended to 'tune' and other senses in some cases. This links to the 'smell/taste' cluster in languages further north, which is discussed in the subsection 'South-Eastern Diffusion'. In southern Arandic, the colexification is with 'hair', which could be linked to the same colexification in the central Gulf of Carpentaria. These are probably generic terms for sections that have been shifted to subsections.

In the Victoria River District, apart from ngurlu with an origin in 'seed', there is another element that may come from 'seed': the suffixes -nginytyu/nginytya, on subsection terms in Jingulu - the first of which is a word for 'seed' in Jingulu. This suggests that there may have been a wider area in which 'seed' was matriclan and later transferred to subsection, with the 'flavour' meaning a later development. ${ }^{13}$

\section{South-Eastern Diffusion}

The subsection terms of south central Arnhem Land are quite divergent from the western ones, and both the southern and eastern pulses into the country of the Gulf of Carpentaria add further divergences, probably indicating an early split in terms. The generic terms for subsection in the south-east diffusion are generally part of the 'smell/taste' cluster; however, at the eastern limits of subsections, we enter the 'hair/head' zone, probably transferred from terms for 'section'.

12 Puntu is probably a loan word from Western Desert with a meaning shift, narrowing from 'person' (earlier < body), or it could be inheritance with meaning shift. Pinti is 'skin' in Warlpiri. This could be $<{ }^{*}$ puntu as ${ }^{*} u>i$ is a known sound change (e.g. *puntaru $>$ pintaru 'quail') but could be a separate item altogether. Warumungu punttu is definitely subsection, with no strict colexification in that language, but there is a verb punttu-ji-na 'get used to', which seems related to the 'relation, companion' sense in Warlpiri.

13 Alpher (2004) listed many cognates of the form ngurlu or ngulu in Pama-Nyungan with the meaning 'forehead' and/or 'face', including urle in Arrernte (with regular initial dropping). Kaytetye, a divergent northern Arandic language, has another cognate erlwe 'eye' = 'seed'. The 'eye/seed' polysemy is well known in Australia and elsewhere (Brown \& Witkowski 1981, 1983), as is 'eye/face' and 'forehead/face'. 


\section{North-Eastern Diffusion}

The western branch of the north-east diffusion in Iwaidjan, western Gunwinyguan, and Wardaman is characterised by the 'dermis' colexification of subsection. This is familiar to us through the Aboriginal English use of 'skin' for subsection (also, skin < Eng. 'skin' in Kriol), which we argue in the next section had its origin in Iwaidjan. For some languages, there is some risk that reports of 'skin' generic terms for 'subsection' might have resulted from back translation by informants inspired by Aboriginal English, Pidgin or Kriol. However, this was generally not the case.

In eastern Gunwinyguan and other languages in central Arnhem Land, the term malk is used for subsection and this term itself diffuses east into other languages including Yolngu Matha (maalk), along with diffusion of the subsection terms themselves up to the mid-twentieth century. The term is very different in meaning from other clusters that we have encountered and apparently polysemous in multiple ways. One of the leading senses is 'country', but this does not seem to relate to any preexisting social category system, as far as can be determined. The most likely social categories that have relationships with areas of country are patrimoieties and semi-moieties.

There is an area in south-eastern Arnhem Land where the subsection diffusion never reached. This is in an area where there are semi-moieties. Semi-moieties operated in conjunction with subsections elsewhere-for instance, further south-east along the Gulf.

Another area to which subsections diffused in the last century is the Daly River/Port Keats (Wadeye) region-although subsections are no longer in use there. In this area, generic subsection terms were adopted from matrilineal totemic clans that were called 'body smell' (various terms).

\section{Overall Historical Explanation of Generic Subsection Terms Pattern}

Close to the subsections origin area on the western side, there are some examples of 'body/flesh' generics extending south-west; however, there is an area where either generics as such are missing or the term for matriclan (also polysemous with 'seed'), a pre-existing social category system, has taken over. One possibility is that the 'body/flesh' generic was the earliest 
throughout the area and then the matriclan generic was adopted. The fact that this term was used for two different social categories may have weakened it in the meaning 'subsection'.

On the eastern side of the origin area in north-central Arnhem Land, 'skin' is the most common subsection generic. Its semantic relation to 'body' on the western side of the origin area may be relevant here; however, the 'body/dermis' colexification is not found in northern Australia unlike many Pacific areas. South-east of the 'skin' area is the central Arnhem Land region in which malk is the prime generic term for subsection, with a set of meanings around 'country'. The term subsequently spread east in the nineteenth and twentieth centuries.

Outside this central area of diffusion, encounters with other pre-existing social category systems probably determined the choice of generic terms for subsections. To the south-east, there is a large arc from the western Gulf of Carpentaria to northern Central Australia in which 'smell/taste' dominates. Beyond that in the eastern Gulf and southern Arandic, 'hair/ head' is the favoured cluster, probably reflecting generic terms for the earlier sections in that area at the limits of subsection spread.

\section{‘Skin’ Enters English}

As previously noted, there is an area in north-western Arnhem Land in which the colexification of subsection is 'skin'. This area also overlaps the area of matrilineal clans that were also called by the local word for 'skin (dermis)' in at least one language-Iwaidja. This is the source of the word 'skin' in Pidgin English, then Kriol (skin) and Aboriginal English and then partially in Australian English more generally.

There was a British presence on the Cobourg Peninsula from the midnineteenth century, with a military settlement at Port Essington in the 1840s. There were Aboriginal people visiting and living at this settlement in this period and Pidgin English, based on New South Wales Pidgin, was being used as a lingua franca. ${ }^{14}$ As early as 1828 , Captain Barker recorded forms of subsection terms on Cobourg Peninsula, namely Nagary and

14 Initial communications were in Macassan Pidgin or Malay but within a short time of the settlement being established, and certainly by the late 1840s, an English-based Pidgin was the main language of communication between the whites and local Aborigines (Harris 1985, pp. 165-6). 
Nakila at Raffles Bay. These are similar to recent forms used in Marrgu/ Iwaidja $\mathrm{Na-ngarrij}$ and $\mathrm{Na}$-angila. In 1847, Confalionieri, a shipwrecked Catholic priest, recorded the subsection term Nagoyo in Garig at Port Essington. ${ }^{15}$ This is evidence that subsections were in use in the region from early in the nineteenth century.

In 1895-1905, Joe Cooper, a white buffalo hunter, had camps on Melville Island among the Tiwi and on Cobourg Peninsula working with Iwaidjan speakers. In 1905, he took a party of Iwaidjan speakers to work with him on Melville Island and they stayed until 1914. Cooper married an Iwaidjan woman and had children including a son Reuben, who set up a sawmill on the Cobourg Peninsula. Cooper was visited by the anthropologist Baldwin Spencer in 1910 and 1912. Spencer collected details of the social organisation of the Iwaidjan groups, the Tiwi and others. The information gathered included subsections and matrilineal social categories. The Iwaidjan groups had subsections, matriclans and matriphratries, while the Tiwi had matrilineal categories and no subsections. Spencer and Gillen (1904) recorded the Pidgin term 'skin (dermis)' being used for matriphratries among the Tiwi, and for both matriphratries and subsections among the Iwaidjan speakers.

Spencer did not record the generic subsection or matriphratry terms among Iwaidjan groups, but it is, and has been for a long time, the term for 'dermis' in the local language (-ngurlhi). However, he did record the generic term for matriphratries among the Tiwi, pukui, which translates as 'sun'-a completely different colexification from any of the other social category terms that we have found in northern Australia. Spencer and Gillen (1912) noted the use of the term 'skin (dermis)' for this category in English among the Tiwi by the first decade of the twentieth century:

The members of groups that are amandinni are supposed to belong to the same 'skin', or pukui, and may not intermarry.

The origin of the term 'skin' among the Tiwi can certainly be ruled out because they did not use a term for 'skin' generically for any social category, and they do not have subsections, which is the prime referent of 'skin' in general usage. The two groups of languages that did use a term for dermis as the generic term for subsections and matriphratries were

15 The current term is Na-wuyuk but this is the form Na-kuyuk. This indicates that the sound change of medial lenition ${ }^{*} k>w$ took place after 1847 (cf. Evans 1997, p. 257). Confalonieri glossed this as 'father' but this is clearly a mistake, as he did not understand subsections. 
Iwaidjan in the Cobourg Peninsula and some central Gunwinyguan languages in Arnhem Land, adjacent to the Cobourg Peninsula. Of these, the Iwaidjan languages are most likely to be the source of transfer of the term 'skin' to Pidgin English, based on the model of local language colexification. There was white settlement from the mid-nineteenth century and intensive interaction between the Iwaidjan, Tiwi and other Aboriginal groups and Joe Cooper on the Cobourg and Melville Island at the end of the nineteenth and early twentieth centuries, with attestation of use of the Pidgin term in the latter period. Since this is the earliest report of use of the term 'skin' for social categories, and there is a colexification of 'dermis' and 'subsection/matriphratry' precisely in the area of the Cobourg Peninsula Iwaidjan languages, we propose that this was the origin of the term. From around the turn of the century, the term 'skin' spread in Pidgin, Aboriginal English and general parlance through the Northern Territory, and into other areas such as the Pilbara and Queensland where it was used to mean other social categories such as sections and moieties (Sharp 1939, p. 442), even though dermis is not the local term in the languages of any of these areas.

This polysemy of the local language words among northern Gunwingguan groups is likely to have been borrowed from Iwaidjan neighbours, as it only affects a restricted area close to Iwaidjan, and other western and eastern Gunwinguan languages have different colexifications. The association of matrilineal social categories with dermis may be ancestral in the Iwaidjan family, although it was extended to subsections much later, perhaps in the last 200-300 years.

The Gunwinyguan groups that used the 'dermis' colexification in their traditional languages are less likely to have been the source of the Pidgin/ English term. In his account of his stay with Paddy Cahill at Oenpelli on the east Alligator River in 1911, Spencer (1928) took down a lot of ethnographic information. He clearly stated that subsections were not in use among the Kakadu or other groups resident in that area, and there is no mention of the term for 'dermis' being used (see Mulvaney 2004). There was less interaction with the white settlement in the late nineteenth century in the mainland areas with the dermis colexification, so it is less likely to have started in that period. However, this would have been fertile ground for initial expansions of the Pidgin/English skin generic term. 


\section{Conclusions}

This chapter has described the terms used to refer to subsections generically throughout the ambit of that system of social categories in northern and Central Australia. One of these generic terms has come into Aboriginal English and English more generally: skin. Terms for 'dermis' were not generally used in traditional Indigenous languages for subsection. However, we propose that polysemy (colexification) between 'dermis' and 'social category', including 'subsection', was present in the Iwaidjan family of languages and some Gunwinyguan neighbours, and then spread into Pidgin around the Cobourg Peninsula during early contact with the British settlement on the Cobourg Peninsula in the mid-nineteenth century, and thence more widely into Aboriginal English and Kriol.

Apart from 'dermis', some other 'body' terms colexify 'subsection' more widely-a prime example being 'body' itself. 'Body' commonly colexifies 'person', and in a couple of cases 'person' or a derivative is the word for subsection. Items related to 'head', such as 'face' and 'hair', are also generic terms for subsection in some areas. These express a distinctive feature of a personal identity. In addition, there is a link to another cluster of generic terms for subsection, 'smell/taste', through the important indicator of personal identity in most Australian cultures 'body/sweat smell', which is colexified with other descriptors of individual identity of cultural elements such as 'tune'. The 'taste' meaning is related etymologically to 'seed' in the Victoria River District and Barkly Tableland. A different cluster is found in central Arnhem Land that is linked to concepts like 'country'-perhaps again through personal identity; however, further research is required.

This chapter has analysed polysemies using knowledge and methods from various disciplines, considering linguistic facts that have included semantic analysis along with historical and geographical linguistic comparisons, cultural practices and social history. Combining disciplines highlights semantic correlations and historical developments that could not have been unveiled otherwise. From the point of view of linguistic methodology, this chapter was the opportunity to use and test a type of 'semantic map' originally developed by François (2008). In this particular instance, the semantic map, which links together colexifications, fits together very neatly with the geographical distributions of the different clusters. The history of the origin and diffusion of subsections is quite well known as it is relatively recent and has been investigated via linguistic 
means. The chapter includes a first attempt to link this historical expansion to the history of spread of the colexification clusters of subsection generic terms. One of the features of this development has been that colexifications of other earlier social categories such as matriphratries and patrimoieties were taken over by the new subsections as they diffused into these areas.

\section{References}

Alpher, B 2004, 'Pama-Nyungan: Phonological reconstruction and status as a phylogenetic group', in C Bowern \& H Koch (eds), Australian languages: classification and the comparative method, Amsterdam: John Benjamins, pp. 93-126, 187-570, 681-6. doi.org/10.1075/ cilt.249.09alp.

Brown, C \& Witkowski, S 1981, 'Symbolism and cognition', American Ethnologist, 8(3), pp. 596-615. doi.org/10.1525/ae.1981. 8.3.02a00110.

Brown, C \& Witkowski, S 1983, 'Polysemy, lexical change and cultural importance', Man, 18, pp. 72-89. doi.org/10.2307/2801765.

Evans, N 1992a, 'Multiple semiotic systems, hyperpolysemy, and the reconstruction of semantic change in Australian languages', in G Kellerman \& M Morrissey (eds), Diachrony within synchrony, Bern: Peter Lang Verlag, pp. 475-508.

Evans, N 1992b, Kayardild dictionary and thesaurus: a vocabulary of the language of the Bentinck Islanders, north-west Queensland, Parkville: University of Melbourne.

Evans, N 1997, 'Macassan loans and linguistic stratification in western Arnhem Land', in P McConvell \& N Evans (eds), Archaeology and linguistics: Aboriginal Australia in global perspective, Melbourne: Oxford University Press, pp. 237-260.

Evans, N 2003, Bininj Gun-Wok: a pan-dialectal grammar of Mayali, Kunwinjku and Kune, Canberra: Pacific Linguistics.

Evans, N \& Wilkins, D 2000, 'In the mind's ear: the semantic extensions of perception verbs in Australian languages', Language, 76(3), pp. 546-92. doi.org/10.2307/417135. 
Evans, N \& Wilkins, D 2001, 'The complete person: networking the physical and the social', in J Simpson, D Nash, M Laughren, P Austin \& B Alpher (eds), Forty years on: Ken Hale and Australian languages, Canberra: Pacific Linguistics, pp. 493-521.

François, A 2008, 'Semantic maps and the typology of colexification: intertwining polysemous networks across languages', in M Vanhove (ed.), From polysemy to semantic change, Amsterdam/Philadelphia: John Benjamins, pp. 163-215. doi.org/10.1075/slcs.106.09fra.

Harris, J 1985, 'Contact languages at the Northern Territory British military settlements 1814-1849', Aboriginal History, 9, pp. 148-69.

Harvey, M 2008, Proto-Mirndi: a discontinuous language family in Northern Australia, Canberra: Pacific Linguistics.

Haspelmath, M 2003, 'The geometry of grammatical meaning: semantic maps and cross-lingusitic comparison', in M Tomasello (ed.), The new psychology of language, vol. 2, Mahwah: Lawrence Erlbaum, pp. 211-43.

Jurafsky, D 1996, 'Universal tendencies in the semantics of the diminutive', Language, 72(3), pp. 533-78. doi.org/10.2307/416278.

Kirton, JF \& Timothy, N 1977, 'Yanyuwa concepts relating to "skin"', Oceania, 47(4), pp. 320-2. doi.org/10.1002/j.1834-4461.1977.tb 01302.x.

Maddock, K 1969, The Jabuduruwa: a study of the structure of rite and myth in an Australian Aboriginal religious cult on the Beswick Reserve, Northern Territory, PhD thesis, University of Sydney.

McConvell, P 1985a, 'The origin of subsections in Northern Australia', Oceania, 56(1), pp. 1-33. doi.org/10.1002/j.1834-4461.1985.tb 02105.x.

McConvell, P 1985b, 'Time perspective in Aboriginal Australian culture', Aboriginal History, 9, pp. 53-80.

McConvell, P 1996, 'Backtracking to Babel: the chronology of Pama-Nyungan expansion in Australia', Archeology in Oceania, 31, pp. 125-44. doi.org/10.1002/j.1834-4453.1996.tb00356.x. 
McConvell, P 1997, 'Long lost relations: Pama-Nyungan and northern kinship', in P McConvell \& N Evans (eds), Archeology and linguistics: Aboriginal Australia in globalperspective, Melbourne: Oxford University Press, pp. 207-36.

McConvell, P 2013, 'Proto-Pama-Nyungan kinship and the AustKin project: reconstructing proto-terms for "mother's father" and their transformations', in P McConvell, I Keen \& R Hendery (eds), Kinship systems: change and reconstruction, Salt Lake City: University of Utah Press, pp. 190-214.

McConvell, P \& Dousset, L 2012, 'Tracking the dynamics of kinship and social category terms with AustKin II', Proceedings of the EACL 2012 Joint Workshop of LINGVIS \& UNCLH, Avignon, France, pp. 98-107.

McConvell, P \& Laughren, M 2004, 'Ngumpin-Yapa subgroup', in $\mathrm{H}$ Koch \& C Bowern (eds), Australian languages: classification and the comparative method, Amsterdam: Benjamins, pp. 151-78. doi.org/ $10.1075 /$ cilt.249.11 mcc.

McConvell, P \& Ponsonnet, M 2013, 'Review of From polysemy to semantic change (Vanhove 2008)', Journal of Language Contact, 6(1), pp. 180-96. doi.org/10.1163/19552629-006001004.

McConvell, P \& Smith, M 2003, 'Millers and mullers: the archaeolinguistic stratigraphy of seed-grinding in Central Australia', in $\mathrm{H}$ Andersen (ed.), Language contacts in prehistory: studies in stratigraphy, Amsterdam: John Benjamins, pp. 177-200. doi.org/10.1075/cilt. $239.14 \mathrm{mcc}$.

Mulvaney, J 2004, Paddy Cahill of Oenpellu, Canberra: Aboriginal Studies Press.

Musharbash, Y (ed.) 2008, Yuendumu everyday: contemporary life in a remote Aboriginal settlement, Canberra: Aboriginal Studies Press.

Pensalfini, R 2003, A grammar of Jingulu: an Aboriginal language of the Northern Territory, Canberra: Pacific Linguistics.

Ponsonnet, M 2009, 'Aspects of the semantics of intellectual subjectivity in Dalabon (south-western Arnhem Land)', Australian Aboriginal Studies, 1, pp. 16-28.

Ponsonnet, $\mathrm{M}$ in prep., Nominal subclasses in Dalabon (south western Arnhem Land). 
Richards, E \& Hudson, J 1990, Walmajarri-English dictionary, Darwin: SIL.

Ross, M 2007, 'Calquing and metatypy', Journal of Language Contact, 1, pp. 116-43. doi.org/10.1163/000000007792548341.

Saulwick, A 2003, A first dictionary of Rembarrnga, Maningrida: Bawinanga Aboriginal Corporation, Maningrida Arts and Culture.

Schapper, A, San Roque, L \& Hendery, R 2016, 'Tree, firewood, and fire in the languages of Sahul', in M Koptjevskaya-Tamm \& P Juvonen (eds), Lexico-typological approaches to semantic shift and motivation pattern, Berlin: De Gruyter.

Sharp, LR 1939, 'Tribes and totemism in north-east Australia', Oceania, 9(3-4), pp. 254-65, 439-61. doi.org/10.1002/j.1834-4461.1939. tb00232.x.

Spencer, B 1928, Wanderings in wild Australia, London: Macmillan \& Co.

Spencer, B \& Gillen, FJ 1904, The northern tribes of Central Australia, London: Macmillan \& Co.

Spencer, B \& Gillen, FJ 1912, Across Australia, London: Macmillan \& Co.

Sweetser, E 1990, From etymology to pragmatics: metaphorical and cultural aspects of semantic structure, Cambridge: Cambridge University Press. doi.org/10.1017/CBO9780511620904.

Testart, A 1978, Des classifications dualistes en Australie, Paris/Lille: Maison des Sciences de l'Homme/Lille III.

von Brandenstein, CG 1982, Names and substance in the Australian subsection system, Chicago: University of Chicago Press. doi.org/ 10.4000/books.editionsmsh. 5757.

Wilkins, D 1996, 'Natural tendencies of semantic change and the search for cognates', in M Durie \& M Ross (eds), The comparative method reviewed: regularity and irregularity in language change, Oxford: Oxford University Press, pp. 264-304.

Wrigley, M 1992, Jaru dictionary, Draft edition, June, Halls Creek: Kimberley Language Reseource Centre. 
This text is taken from Skin, Kin and Clan: The dynamics of social categories in Indigenous Australia, edited by Patrick McConvell, Piers Kelly and Sébastien Lacrampe, published 2018 by ANU Press, The Australian National University, Canberra, Australia.

doi.org/10.22459/SKC.04.2018.09 